\title{
The Pseudomonas Secondary Metabolite 2,4-Diacetylphloroglucinol Is a Signal Inducing Rhizoplane Expression of Azospirillum Genes Involved in Plant-Growth Promotion
}

\author{
Emeline Combes-Meynet, Joël F. Pothier, Yvan Moënne-Loccoz, and Claire Prigent-Combaret \\ Université de Lyon, F-69622, Lyon, France; Université Lyon 1, Villeurbanne, France; and CNRS, UMR5557, Ecologie \\ Microbienne, Villeurbanne, France
}

Submitted 2 July 2010. Accepted 26 October 2010.

\begin{abstract}
During evolution, plants have become associated with guilds of plant-growth-promoting rhizobacteria (PGPR), which raises the possibility that individual PGPR populations may have developed mechanisms to cointeract with one another on plant roots. We hypothesize that this has resulted in signaling phenomena between different types of PGPR colonizing the same roots. Here, the objective was to determine whether the Pseudomonas secondary metabolite 2,4-diacetylphloroglucinol (DAPG) can act as a signal on Azospirillum PGPR and enhance the phytostimulation effects of the latter. On roots, the DAPG-producing Pseudomonas fluorescens F113 strain but not its $p h l$-negative mutant enhanced the phytostimulatory effect of Azospirillum brasilense Sp245-Rif on wheat. Accordingly, DAPG enhanced Sp245-Rif traits involved in root colonization (cell motility, biofilm formation, and poly- $\beta$-hydroxybutyrate production) and phytostimulation (auxin production). A differential fluorescence induction promoter-trapping approach based on flow cytometry was then used to identify Sp245-Rif genes upregulated by DAPG. DAPG enhanced expression of a wide range of Sp245-Rif genes, including genes involved in phytostimulation. Four of them (i.e., ppdC, flgE, nirK, and nifX-nifB) tended to be upregulated on roots in the presence of $P$. fluorescens F113 compared with its $p h l$-negative mutant. Our results indicate that DAPG can act as a signal by which some beneficial pseudomonads may stimulate plant-beneficial activities of Azospirillum PGPR.
\end{abstract}

The rhizosphere is a very active microbial habitat driven by the organic substrates released by the plant as root exudates (Bais et al. 2006). Trophic conditions are important in determining the assembly and functioning of the rhizosphere microbial community (Bjørnlund et al. 2006). However, the ecology of rhizosphere microorganisms is also influenced by the synthesis of inhibitory plant and microbial compounds involved in

Current address for J. F. Pothier: Research Station Agroscope ChanginsWädenswil, Plant Protection Division, CH-8820 Wädenswil, Switzerland.

Corresponding author: C. Prigent-Combaret; Telephone: +33 4724458 89; Fax: +33 4724312 23; E-mail: claire.prigent-combaret@univ-lyon1.fr

Sequences obtained in the current work are deposited under accession numbers GU291803 to GU291854.

* The $e$-Xtra logo stands for "electronic extra" and indicates that two supplementary figures are published online. parasitism, antagonism, or competition (Bouwmeester et al. 2007; Couillerot et al. 2009), as well as molecular signals (i.e., low molecular weight compounds that are emitted by an organism and recognized by another at nanomolar to micromolar concentration, and that elicit a response in the latter) (Bais et al. 2006; Hirsch et al. 2003). These signals are important for the establishment of mutualistic and associative interactions between microorganisms and plant roots (Cooper et al. 2007; Pothier et al. 2007).

Mutualistic plant-bacteria interactions have been extensively studied in the case of the nitrogen-fixing symbiosis with legumes or actinorhizal plants and, at least in the former case, the signaling phenomena are well documented (Gibson et al. 2008; Spaink 2000). In contrast, the signaling involved in associative symbiosis between plant-growth-promoting rhizobacteria (PGPR) and roots are poorly understood. Most signaling phenomena studied in the case of multitrophic interactions involving PGPR concern the impact of i) root-secreted compounds on the selection of root-associated bacteria (Ramey et al. 2004) and the control of their plant-beneficial activities (Pothier et al. 2007; Rudrappa et al. 2008; Teplitski et al. 2000); ii) bacterial secondary metabolites, including phytohormones, on root growth and plant defense (Lambrecht et al. 2000; Pieterse et al. 2003); and iii) quorum-sensing pheromones in the regulation of microbe-microbe social relationships (Boyer et al. 2008; Daniels et al. 2006). Because PGPR might have coevolved with plants, it could be that other types of signaling phenomena are also involved when considering the social relations between different types of PGPR colonizing the same roots (Wei and Zhang 2006). However, this possibility has been neglected so far.

Among molecular signals released in the rhizosphere, the Pseudomonas secondary metabolite 2,4-diacetylphloroglucinol (DAPG) is one of the most intriguing compounds synthesized by PGPR. This phenolic was originally studied for its antimicrobial properties, and it was found to be antifungal, antibacterial, antiviral, antihelminthic, and phytotoxic when used at a high concentration (Haas and Keel 2003; Weller 2007). However, at lower concentrations, DAPG acts as a signal molecule influencing gene expression of biocontrol traits in plantprotecting pseudomonads and fungi (Baehler et al. 2005; Brodhagen et al. 2004; Lutz et al. 2004). DAPG can also be a signal molecule for plants, inducing systemic resistance (Iavicoli et al. 2003; Bakker et al. 2007), stimulating root exudation (Phillips et al. 2004), and enhancing branching of the root system via the auxin-dependent plant signaling pathway (Brazelton et al. 2008). Whether it can also have a signaling effect on 
non-Pseudomonas PGPR is not known and was the focus of the current work.

DAPG-producing pseudomonads play an important role in disease-suppressive soils, where plants are protected from soilborne diseases by naturally occurring microbial populations (Frapolli et al. 2008; Weller et al. 2007). In microarray comparisons of indigenous populations in soils suppressive or conducive to tobacco black root rot or wheat take-all, it came as a surprise that species of Azospirillum, a key genus of phytostimulatory PGPR, colonized roots jointly with DAPG-producing pseudomonads in suppressive soils (Kyselková et al. 2009; Sanguin et al. 2009). Azospirillum PGPR display various plantbeneficial traits; i.e., production of nitric oxide (Creus et al. 2005) and auxin phytohormones (Costacurta and Vanderleyden 1995), ACC deaminase activity (Prigent-Combaret et al. 2008), associative nitrogen fixation (Bally and Elmerich 2007), and control of parasitic plants (Miché et al. 2000) and bacteria (Bashan and de-Bashan 2002). Their phytostimulatory effects have been shown under greenhouse experiments and field conditions (Dobbelaere et al. 2001; El Zemrany et al. 2006). The possibility that biocontrol Pseudomonas PGPR could interact with Azospirillum PGPR has been shown before (Naiman et al. 2009; Vázquez et al. 2000) but the mechanisms involved remain to be identified.

In this work, our goal was to determine whether DAPG can act as a signal molecule on Azospirillum spp. To this end, the impact of the DAPG production ability of fluorescent Pseudomonas spp. on the phytostimulatory effect of Azospirillum brasilense Sp245-Rif on wheat was analyzed. In addition, the impact of DAPG on traits involved in Sp245-Rif root colonization and plant-growth promotion was evaluated in vitro. Finally, strain Sp245-Rif was exposed to DAPG at concentrations found in the rhizosphere, and a differential fluorescence induction (DFI) approach (Allaway et al. 2001) based on fluorescence-activated cell sorting (FACS) was then used to identify $\mathrm{Sp245-Rif} \mathrm{genes} \mathrm{upregulated} \mathrm{in} \mathrm{the} \mathrm{presence} \mathrm{of} \mathrm{DAPG.}$

\section{RESULTS}

\section{Effect of Pseudomonas fluorescens F113 and its $p h l$-negative mutant F113G22}

on plant growth promotion by $A$. brasilense Sp245-Rif.

Under gnotobiotic conditions, root development of spring wheat inoculated with $A$. brasilense Sp245-Rif alone was significantly better at 7 days than that of noninoculated plants based on total root length, average root diameter, root surface area, or total root volume (Table 1). Coinoculation of A. brasilense Sp245-Rif with DAPG-producing strain $P$. fluorescens F113 led to plant root development that, depending on the measurement, was comparable (for total root length and root surface area) or enhanced (for average root diameter, total root volume, and number of roots) in comparison with that obtained with strain Sp245-Rif alone. When phl-negative mutant P. fluorescens F113G22 was used instead of P. fluorescens F113 in coinoculation with A. brasilense Sp245-Rif, a trend (not significant at $P<0.05$ however) for a decrease of plant root development was observed, leading to results comparable with those recorded when using strain Sp245-Rif alone. This trend was not linked to differences in Azospirillum root colonization levels, because A. brasilense Sp245-Rif was recovered at $6.2 \pm 0.8$ (inoculated singly), $6.7 \pm 0.4$ (in the presence of $P$. fluorescens $\mathrm{F} 113$ ), and $6.5 \pm 0.6 \log \mathrm{CFU}$ plant $^{-1}$ (in the presence of $P$. fluorescens $\mathrm{F} 113 \mathrm{G} 22$ ) from wheat roots at 7 days (Table 1).

\section{Effect of synthetic DAPG on selected Sp245-Rif phenotypes.}

As an effort to understand the enhanced plant growth-promoting effect of Sp245-Rif/F113 coinoculation, the impact of DAPG on several Sp245-Rif traits implicated in root colonization and plant growth promotion was analyzed in vitro. None of the DAPG concentrations tested up to $500 \mu \mathrm{M}$ resulted in Azospirillum growth inhibition, whereas growth was affected at 1,000 $\mu \mathrm{M}$ DAPG (Supplementary Fig. S1). DAPG had no effect on Azospirillum swarming (data not shown), whereas swimming of strain Sp245-Rif was significantly higher at intermediate DAPG concentrations of 0.01 and $1 \mu \mathrm{M}$ but lower again at $0.1 \mu \mathrm{M}$ DAPG (Fig. 1). This increase only at two intermediate DAPG concentrations was confirmed on two other occasions (data not shown). Biofilm formation on polystyrene reached a maximum for an intermediate DAPG concentration of $0.1 \mu \mathrm{M}$ (Fig. 2). Cell accumulation of poly- $\beta$ hydroxybutyrate (PHB) storage material increased linearly with DAPG concentration (Fig. 3), which was confirmed by epifluorescence microscopic observations.

\section{DFI identification}

of $A$. brasilense promoters upregulated by DAPG.

The signaling effect of DAPG on the A. brasilense Sp245Rif transcriptome was thereafter analyzed using a promotertrapping approach. When the promoter-trap library PTL-AbP of strain Sp245-Rif (Pothier et al. 2007) was screened for promoters upregulated by DAPG, flow cytometry cell sorting gave 1,920 DFI clones at $0.01 \mu \mathrm{M}$ DAPG and 960 at $10 \mu \mathrm{M}$ DAPG. DAPG induction of the most fluorescent DFI clones was confirmed in microtiter plates (at the corresponding DAPG concentration) in two independent experiments. Among them, 158 (at $0.01 \mu \mathrm{M}$ DAPG) and 60 (at $10 \mu \mathrm{M}$ DAPG) DFI clones displayed an induction factor higher than 1.5 in both microtiter plate experiments. Sequence comparison of 96 DFI

Table 1. Effects of single or double inoculation with Azospirillum brasilense Sp245-Rif, 2,4-diacetylphloroglucinol (DAPG)-producing Pseudomonas fluorescens F113, or its phl-negative mutant F113G22 on root system development of wheat at 7 days (mean \pm standard error, $n=5)^{\mathrm{x}}$

\begin{tabular}{|c|c|c|c|c|c|c|}
\hline \multirow[b]{2}{*}{ Root system parameters } & \multirow[b]{2}{*}{ Control $^{\mathrm{y}}$} & \multicolumn{3}{|c|}{ Single inoculation } & \multicolumn{2}{|c|}{ Pseudomonas co-inoculated with Sp245-Rif } \\
\hline & & Sp245-Rif & F113 & F113G22 & F113 & F113G22 \\
\hline Total root length (cm plant ${ }^{-1}$ ) & $15.4 \pm 2.6 b$ & $28.1 \pm 2.4 \mathrm{a}$ & $18.9 \pm 3.3 b$ & $24.3 \pm 3.2 \mathrm{ab}$ & $30.6 \pm 2.7 \mathrm{a}$ & $27.9 \pm 1.8 \mathrm{a}$ \\
\hline Root surface area $\left(\mathrm{mm}^{2}\right.$ plant $\left.^{-1}\right)$ & $347 \pm 66 c$ & $738 \pm 72 \mathrm{ab}$ & $439 \pm 82 c$ & $519 \pm 75 \mathrm{bc}$ & $932 \pm 76 \mathrm{a}$ & $774 \pm 62 \mathrm{a}$ \\
\hline Average root diameter $(\mathrm{mm})$ & $0.67 \pm 0.04 \mathrm{c}$ & $0.83 \pm 0.02 b$ & $0.74 \pm 0.07 \mathrm{bc}$ & $0.66 \pm 0.04 \mathrm{c}$ & $0.97 \pm 0.03 \mathrm{a}$ & $0.88 \pm 0.04 \mathrm{ab}$ \\
\hline Total root volume $\left(\mathrm{mm}^{3}\right.$ plant $\left.^{-1}\right)$ & $60 \pm 10 \mathrm{~d}$ & $160 \pm 20 \mathrm{bc}$ & $90 \pm 20 \mathrm{~cd}$ & $90 \pm 10 \mathrm{~cd}$ & $230 \pm 20 a$ & $170 \pm 20 \mathrm{ab}$ \\
\hline Number of roots per plant & $24 \pm 5 b$ & $52 \pm 9 \mathrm{~b}$ & $36 \pm 8 b$ & $49 \pm 8 b$ & $101 \pm 16 \mathrm{a}$ & $51 \pm 7 b$ \\
\hline Colonization $\left(\log \mathrm{CFU} \text { plant }^{-1}\right)^{\mathrm{z}}$ & & $6.2 \pm 0.8 b$ & $7.7 \pm 0.5 \mathrm{a}$ & $7.4 \pm 0.3 \mathrm{a}$ & $6.7 \pm 0.4 \mathrm{~b} / 7.6 \pm 0.6 \mathrm{a}$ & $6.5 \pm 0.6 \mathrm{~b} / 7.3 \pm 0.8 \mathrm{a}$ \\
\hline
\end{tabular}

${ }^{x}$ For each data row, statistical differences between treatments are indicated with lowercase letters (analysis of variance and Fisher's least significant difference tests; $P<0.05$ ). Plant parameters were compared between the six treatments (i.e., the noninoculated control, the three single inoculations, and the two double inoculations). For the colonization data, the seven populations evaluated on the roots following single- and double-strain inoculations were compared with each other.

y Noninoculated control.

${ }^{\mathrm{z}}$ Colonization by inoculants. 
clones (i.e., 64 of 158 DFI clones at $0.01 \mu \mathrm{M}$ DAPG and 32 of 60 DFI clones at $10 \mu \mathrm{M}$ DAPG) with the A. brasilense Sp245 whole-genome sequence and GenBank database indicated that 37 of 64 inserts (at $0.01 \mu \mathrm{M}$ DAPG) and 15 of 32 inserts (at 10 $\mu \mathrm{M}$ DAPG) encompassed putative promoters, whereas the 44 others were within putative open reading frames (ORF) or in the opposite direction of predicted genes.

\section{Sequence analysis of DAPG-induced promoters.}

Based on A. brasilense Sp245 genome data and BlastP analyses, the 52 DFI clones corresponding to putative promoters were grouped in seven functional classes according to function prediction of the corresponding ORF located downstream. The first class (cell transport and nutrient scavenging) included three DFI clones (Table 2). Their deduced protein sequences are homologous to i) a secretion protein of the HlyD membrane fusion protein type (clone IID3) and ii) two ABC transporters, LivG (IIIB2) and an iron permease (IIB4).
The second class (central intracellular metabolism) included 16 DFI clones, a majority displaying deduced protein sequences involved in energy production and electron transfer, such as i) cytochrome c551 peroxidase (clones IB1 and IIG4) and cytochrome c peroxidase (IIG6), ii) aconitate hydratase (IIIC6 and IIIF2) implicated in the Krebs and glyoxylate cycles, iii) cytochrome c oxidase (IIID1) and polyphosphate kinase (PPK) (IIA4) relevant for oxidative phosphorylation, and iv) carbon-monoxide dehydrogenase (IF10) (Table 2). For the other clones, the deduced protein sequence is homologous to i) the EutB subunit of the cobalamin-dependent ethanolamine ammonia-lyase (clone IID7), ii) an $\alpha$-D-galactoside galactohydrolase (IIE6), iii) an enoyl-CoA hydratase/isomerase involved in butanoate and PHB metabolism (IIIC1), iv) a malic enzyme catalyzing the anaplerotic reaction supplying pyruvate from malate in the Krebs cycle (IIIA8), v) a UvrD helicase II (IE7), and vi) the translation elongation factor EFG (IID8, IIA8 and IIF3).

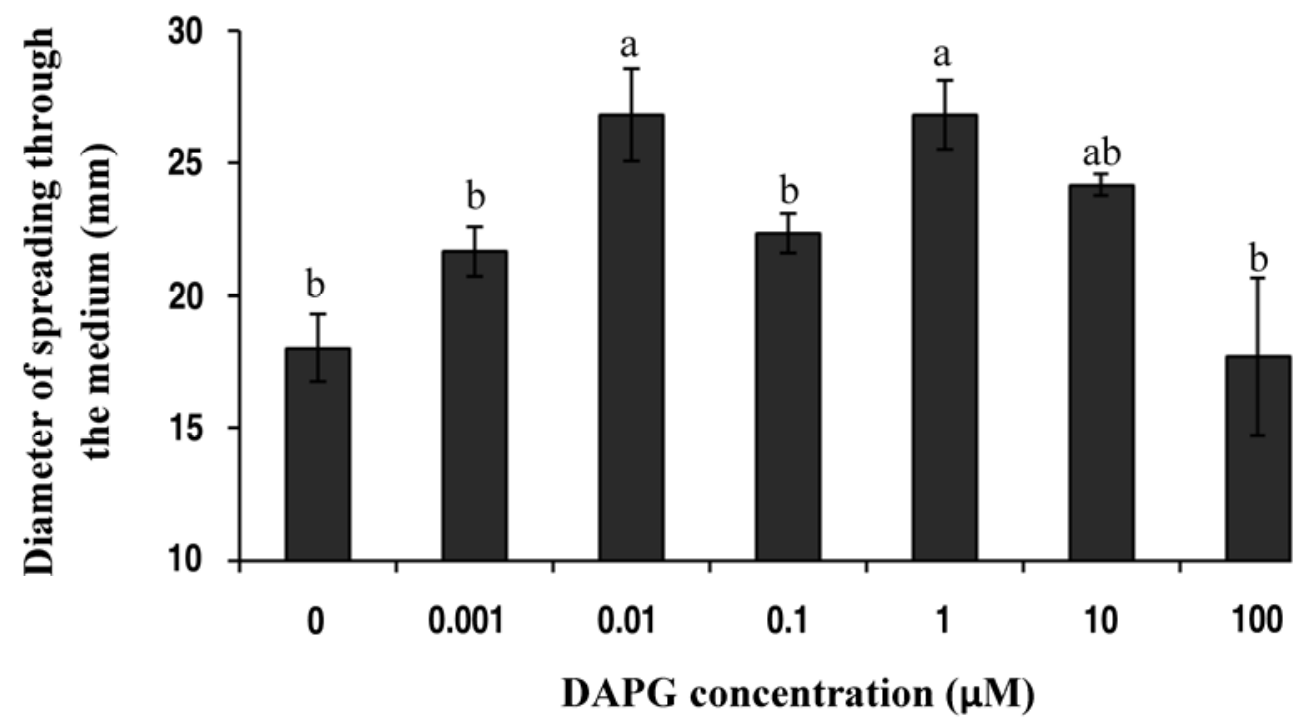

Fig. 1. Effect of synthetic 2,4-diacetylphloroglucinol (DAPG) (0.001 to $100 \mu \mathrm{M})$ on cell motility of Azospirillum brasilense Sp245-Rif on soft agar. Diameters $(\mathrm{mm})$ of spreading through the medium at 3 days are shown as means \pm standard deviation $(n=6)$. Letters indicate significant differences among treatments $(P<0.05)$

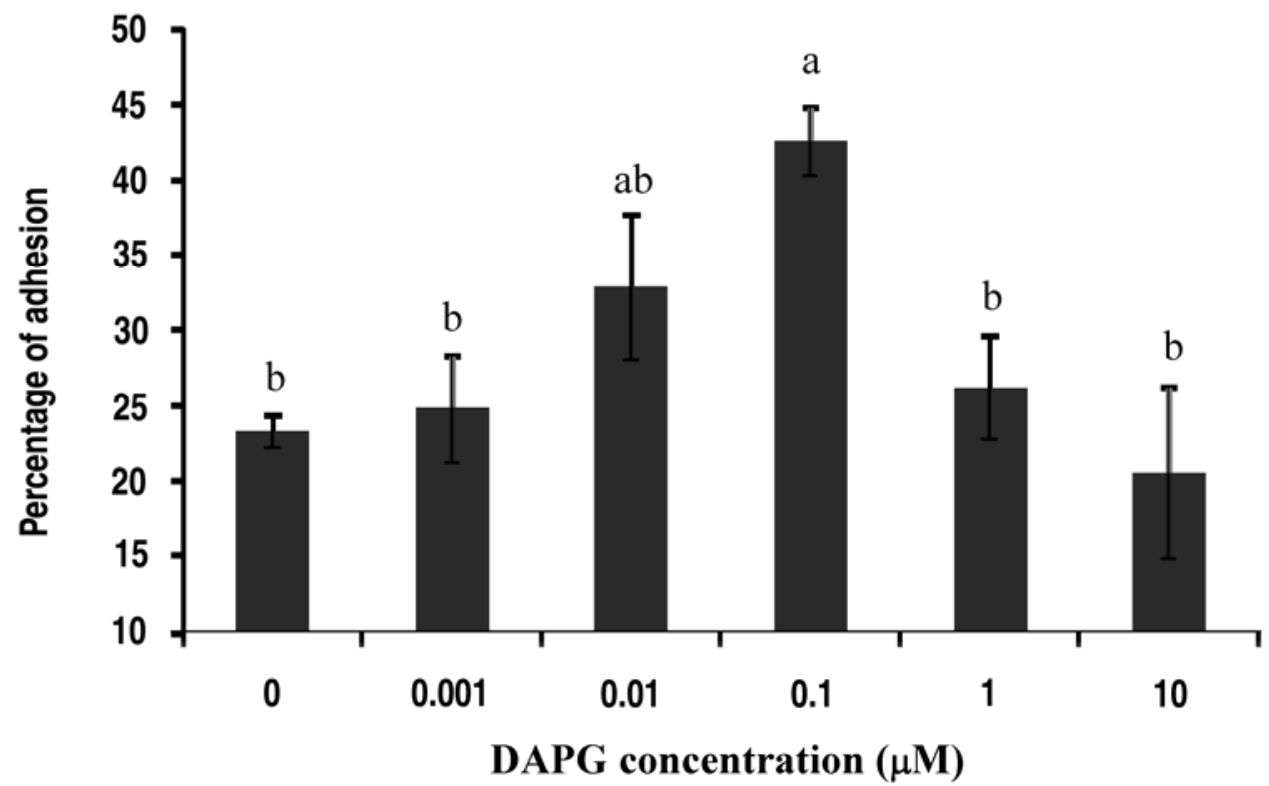

Fig. 2. Effect of synthetic 2,4-diacetylphloroglucinol (DAPG) (0.001 to $10 \mu \mathrm{M})$ on biofilm formation of Azospirillum brasilense Sp245-Rif on polystyrene. Cell adhesion data (at 6 days) are expressed as means \pm standard deviation $(n=8)$. Letters indicate significant differences among treatments $(P<0.05)$. 
The third class (post-translational modification and proteasome) included seven DFI clones (Table 2). Their deduced protein sequences are homologous to i) a post-translational methionine aminopeptidase (clone IIIH7); ii) an M20/M25/ M40 peptidase (IIF5) and a serralysin (IIH4) involved in proteolysis; iii) a periplasmic chaperone corresponding to an outer membrane lipoprotein (IIIC8) and the chaperone Dj1A (IB12 and IA9); and iv) a stress-induced, FtsH protease-controlling band7-stomatin-like protein (IH8).

The fourth class (biotic interactions) included three DFI clones (Table 2). The deduced protein sequence of one of them (clone IB8) is homologous to the nitrogen fixation-related proteins NifX-NifB, which are responsible for synthesis of the iron-molybdenum dinitrogenase cofactor (Rubio and Ludden 2008). Another corresponds to Sp245's own phenylpyruvate decarboxylase-encoding gene, $p p d C$ (clone IIIC3), which is involved in synthesis of phytohormone 3-indole acetic acid (IAA) (Dobbelaere et al. 1999). The deduced protein sequence of the third DFI clone (clone IIA3) is homologous to Sp245's own flagellar hook protein FlgE. The same region was previously identified as upregulated by wheat seed exudates (Pothier et al. 2007). Another A. brasilense Sp245-Rif wheat seed exudate-induced gene (i.e., the nitrite reductase-encoding nirK) was observed as upregulated in the presence of DAPG $(0.01$ $\mu \mathrm{M})$ but this clone was not obtained here by flow cytometry.

The fifth class (transcription regulation) contained five DFI clones (Table 2). They encode putative transcriptional regulators of the XRE (clone IIIE2), AlgH (IF11), AsnC (IIB3), or GntR family (IIC8), or a putative anti- $\sigma$-factor antagonist with a sulfate transporter and anti- $\sigma$ domain (IB4).

The sixth class (stimulus perception and signaling) includes two DFI clones (Table 2). They correspond to a putative CstS1like hybrid sensor kinase/response regulator (clone IIIE5) and a putative adenylate/guanylate cyclase involved in cyclic nucleotide biosynthesis (IIIH5).

The seventh class gathers DFI clones whose predicted amino acid sequences did not give any hit in GenBank search (clones IE12, IC12, IB5, ID8, IIIG1, IH7, and IIF6) or displayed homol- ogy with proteins of unknown function (IE1, IE3, IIID6, IIB7, IIIG6, IIH7, IIG5, IIC4, and IIC6). The deduced protein sequences for four of the latter are homologous to conserved hypothetical proteins with PDZ (i.e., protein-protein interactions), and FIST or CBS domains (i.e., ligand-protein interactions).

\section{Quantification of in vitro DAPG induction of the $A$. brasilense Sp245-Rif ppdC gene expression and indolic compound production.}

The effect of DAPG concentration on expression of IAA gene $p p d C$ was investigated in more detail, this time in the presence of IAA precursor tryptophan. First, fluorescence measurements indicated that expression of the $p p d C$ clone IIIC3 significantly increased with DAPG concentrations between 0.001 and $10 \mu \mathrm{M}$, reaching a maximum at $1 \mu \mathrm{M}$ DAPG (Fig. 4A). Second, a Salkowski colorimetric assay showed that production of IAA and related indole compounds was significantly higher at 0.001 to $1 \mu \mathrm{M}$ DAPG in comparison with the control (Fig. 4B).

\section{In planta expression \\ of four plant-interaction-relevant DFI clones in the presence of $P$. fluorescens F113 or phl-negative mutant F113G22.}

When assessed in planta, four DFI clones of particular relevance for interaction with the plant (i.e., corresponding to $p p d C, f l g E$, nirK, and nifX-nifB) were found both as single cells and large cell clumps at 7 days after inoculation, based on transmitted light observations (data not shown). They were over the whole root system of spring wheat but colonization was higher in the root hair zone.

When inoculated singly, all four DFI clones were fluorescent on roots at 7 days, meaning that the corresponding promoter was transcribed, even though no DAPG-producing bacterium was present (Supplementary Fig. S2). More specifically, $p p d C$ and $f l g E$ were expressed in the root hair zone, nifX-nifB in the root hair zone and on border cells at the root tip, and nirK along the entire root system except the apex.

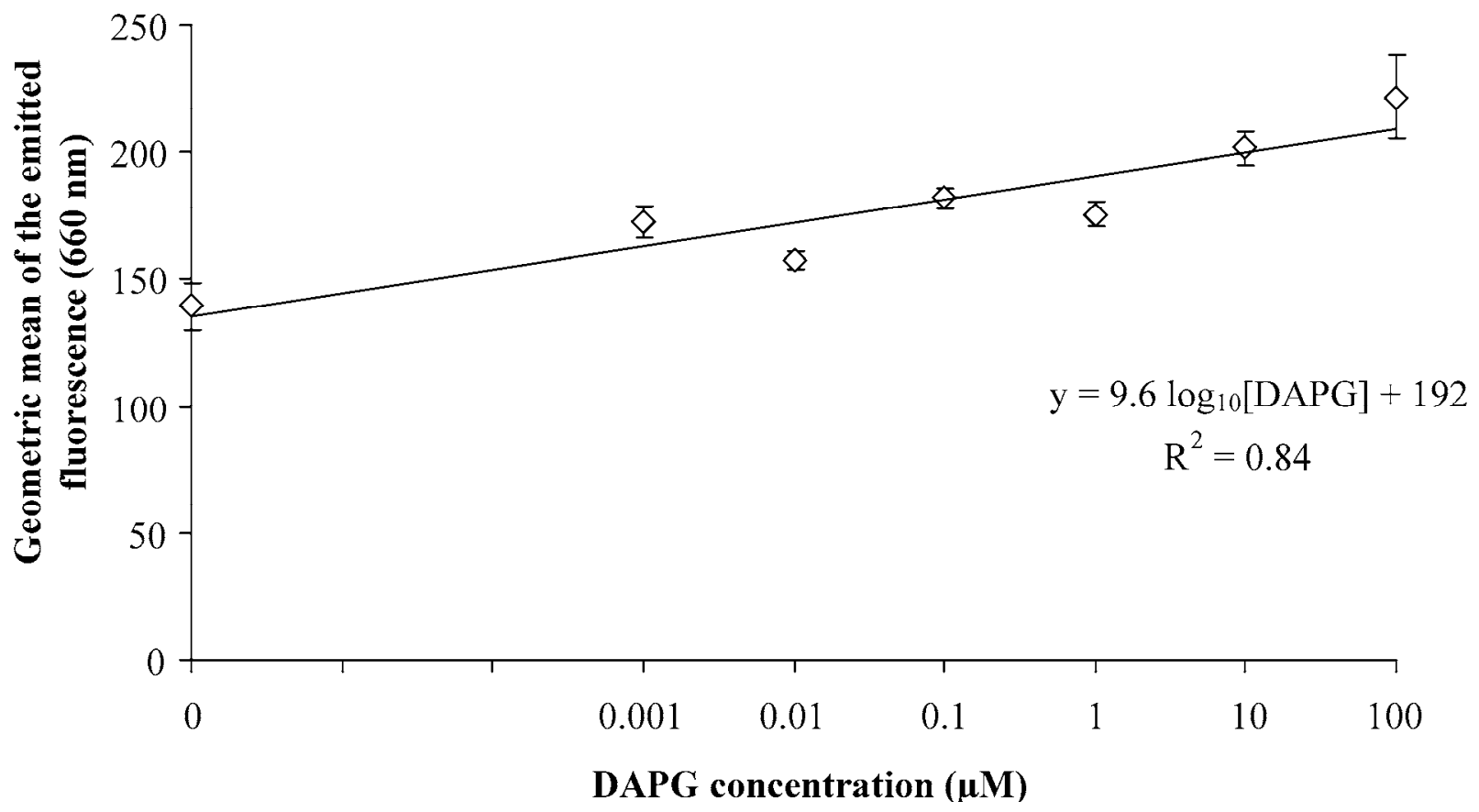

Fig. 3. Effect of synthetic 2,4-diacetylphloroglucinol (DAPG) $(0.001$ to $100 \mu \mathrm{M})$ on poly- $\beta$-hydroxybutyrate accumulation in Azospirillum brasilense Sp245-Rif. Data are expressed as means \pm standard deviation $(n=4)$. The concentration of $0 \mu \mathrm{M}$ DAPG was arbitrarily put at $10^{-6} \mu \mathrm{M}$ DAPG. The linear regression equation and its $R^{2}$ value are shown $(P=0.0037)$. Standard errors were 1.9 (estimated slope) and 4.9 (intercept). 
Qualitative distribution of fluorescent cells on roots at 7 days was not modified when plants had been coinoculated with a pseudomonad 2 days after Azospirillum inoculation; however, the total root surface area with fluorescent cells of the $p p d C$-egfp and $f l g E$-egfp clone was reduced in the presence of P. fluorescens F113G22 (Fig. 5). Lower fluorescence levels of DFI clones at 7 days were observed in the presence of phlnegative mutant F113G22 compared with the control (1.8-fold reduction with $p p d C$ to 5.3 -fold reduction with nirK) but the trend is not significant in the case of the $p p d C$ clone (Fig. 5). In the presence of the DAPG-producing wild-type strain F113, however, fluorescence levels of the four DFI clones were i) like those in the control but ii) higher than those in the presence of the mutant F113G22 (Fig. 5).

\section{DISCUSSION}

This work dealt with the possibility that DAPG production by root-colonizing biocontrol pseudomonads could interfere positively with phytostimulation by Azospirillum PGPR. Indeed, coinoculation of wheat with the DAPG-producing strain P. fluorescens F113 and the PGPR A. brasilense Sp245-Rif resulted in enhanced root diameter, total root volume, and root number in comparison with single Sp245-Rif inoculation (Table 1). For root number, this positive effect did not occur when the phl-negative mutant F113G22 was coinoculated instead of F113, suggesting that DAPG production was involved. One possibility is that DAPG could act directly on the plant. First, DAPG may influence root system architecture, as shown on tomato (Brazelton et al. 2008), but here, neither P. fluorescens F113 strain nor its $p h l$-negative mutant had any effect when inoculated singly. Second, DAPG may also enhance root exudation (Phillips et al. 2004), which might favor Azospirillum spp. survival or functioning. However, the total number of Sp245-Rif cells colonizing wheat roots was not significantly higher in the presence of F113 or F113G22 (Table 1). Third, perhaps the plant physiological responses induced by DAPG (Iavicoli et al. 2003) facilitate plant receptivity to Sp245-Rif's phytohormonal effects; however, this hypothesis was outside the scope of this study.

The other possibility is that DAPG could act as signal on Azospirillum spp. themselves, inducing the expression of plantbeneficial genes, and this was the focus of the current work. To this end, the impact of DAPG on Sp245-Rif transcriptome was

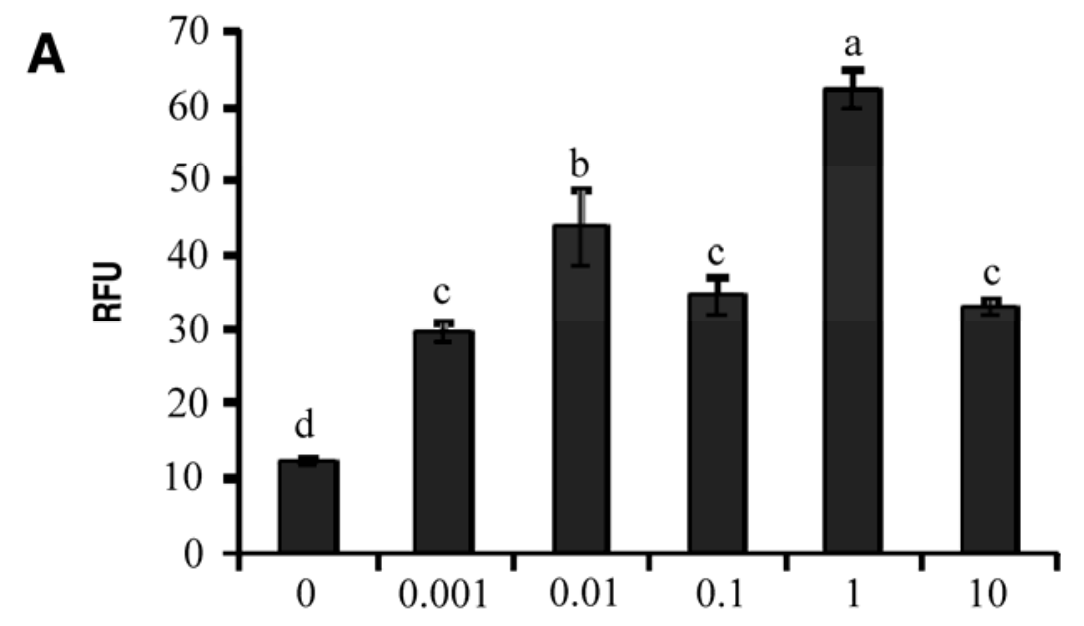

DAPG concentration $(\mu \mathrm{M})$

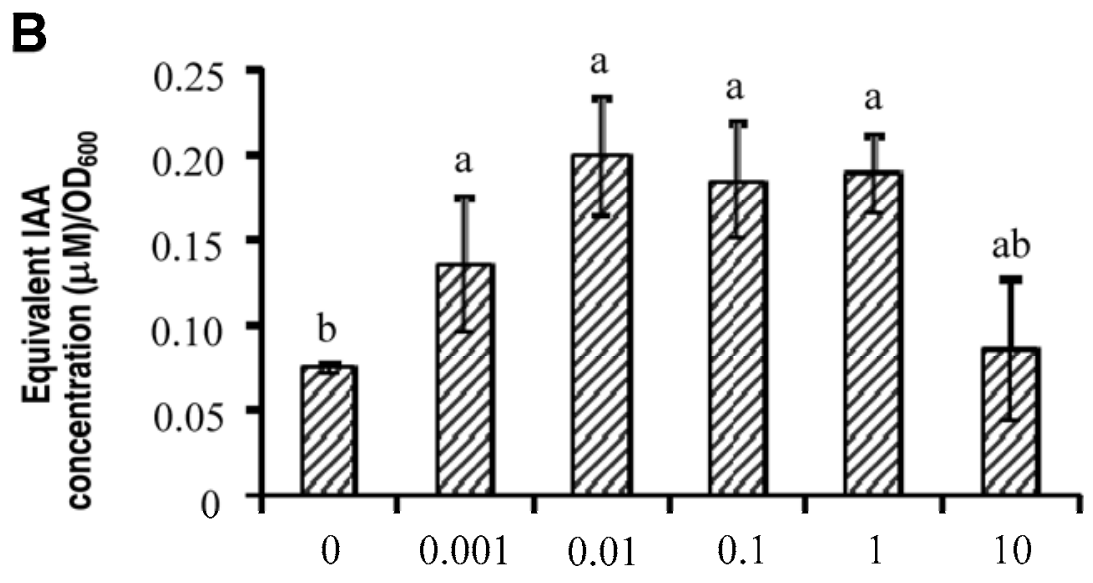

DAPG concentration $(\mu \mathrm{M})$

Fig. 4. Effect of synthetic 2,4-diacetylphloroglucinol (DAPG) $(0.001$ to $10 \mu \mathrm{M})$ on $p p d C$ gene expression and 3-indole acetic acid (IAA) production in differential fluorescence induction clone IIIC 3 of Azospirillum brasilense Sp245-Rif after 6 days in ABmal medium supplemented with tryptophan at $100 \mu \mathrm{g}$ ml ${ }^{-1}$. A, Relative enhanced green protein fluorescence of the ppdC-egfp fusion was quantified using a spectrofluorimeter. B, Equivalent IAA concentration (for IAA and related indole compounds) was obtained using a colorimetric Salkowski method. Data are expressed as means \pm standard deviation ( $n=4)$, and letters indicate significant differences among treatments $(P<0.05)$. 
analyzed by promoter trapping using flow cytometry. This was done at $10 \mu \mathrm{M}$ DAPG, which corresponds to i) average DAPG concentrations reported in the rhizosphere (Bonsall et al. 1997) and ii) concentrations that improve lateral root production in tomato (Brazelton et al. 2008), as well as at a thousand-fold lower concentration $(0.01 \mu \mathrm{M}$ DAPG), which might be relevant to colonization patterns of Azospirillum and Pseudomonas spp. on wheat roots (as both bacteria may colonize spatially distant sites). Indeed, the majority of Sp245-Rif promoters upregulated by DAPG were obtained with $0.01 \mu \mathrm{M}$ DAPG. This is consistent with the concept that DAPG can act on Sp245-Rif as a molecu- lar signal, eliciting a broad cell response at very low concentration. Indeed, several DFI clones obtained at $0.01 \mu \mathrm{M}$ DAPG corresponded to genes involved in signal transduction pathways, such as those encoding the Cst1 response regulator (IIIE5); five transcriptional regulators (IIIE2, IF11, IIB3, IIC8, and IB4), including an anti-anti- $\sigma$ factor (IB4); and four unknown proteins potentially involved in protein-protein interactions (IE1, IE3, IIID6, and IIC4). DAPG also induces a putative adenylate/guanylate cyclase (IIIH5) required for the biosynthesis of cyclic nucleotides, which are cell second messengers that control a wide range of cellular processes (Pesaventoa and Hengge 2009).

Table 2. Potential 2,4-diacetylphloroglucinol (DAPG)-induced promoters identified by differential fluorescence induction (DFI) in Azospirillum brasilense Sp245-Rif

\begin{tabular}{|c|c|c|c|c|c|}
\hline \multirow[b]{2}{*}{ Clone $^{y}$} & \multirow[b]{2}{*}{ Accession no. } & \multirow[b]{2}{*}{ Gene, function } & \multicolumn{2}{|c|}{ Induction level $^{\mathrm{x}}$} & \multirow[b]{2}{*}{ Comparison with closest database sequence ${ }^{\mathrm{z}}$} \\
\hline & & & $0.01 \mu \mathrm{M}$ & $10 \mu \mathrm{M}$ & \\
\hline \multicolumn{6}{|c|}{ Class I: cell transport and nutrient scavenging } \\
\hline IIB4 & GU291813 & $\mathrm{ABC}$ transporter & - & & $\begin{array}{l}\text { Microcoleus chthonoplastes } \mathrm{PCC} 7420 \text { (YP002616034), } \mathrm{ABC} \text { transporter, } \\
\text { permease protein (potentially involved in iron III uptake), 0e } 0,65 \%, 78 \%\end{array}$ \\
\hline IID3 & GU291817 & Secretion protein & - & & $\begin{array}{l}\text { Parvibaculum lavamentivorans DS-1 (YP001412779), HlyD-family } \\
\text { secretion protein (COG0845, coiled-coil domain), 5e-116, 65\%, } 81 \%\end{array}$ \\
\hline IIIB2 & GU291827 & $\operatorname{liv} G$ & & $\mathbf{m} \mathbf{m}$ & $\begin{array}{l}\text { Desulfovibrio vulgaris subsp. vulgaris Hildenborough (YP009936), } \\
\text { branched-chain amino acid ABC transporter, ATP-binding protein, 3e-66, } \\
50 \%, 68 \%\end{array}$ \\
\hline \multicolumn{6}{|c|}{ Class II: central metabolis } \\
\hline IID8** & GU291818 & fusA & - & & $\begin{array}{l}\text { Rhodospirillum centenum } \text { SW (YP002298082), translation elongation } \\
\text { factor, EF-G (GTPases, COG0480), 0e-0, 62\%, 78\% }\end{array}$ \\
\hline IIA $8 *$ & GU291812 & fusA & - & & $\begin{array}{l}\text { R. centenum SW (YP002298082), translation elongation factor, EF-G } \\
\text { (GTPases, COG0480), 0e-0, 62\%, 78\% }\end{array}$ \\
\hline $\mathrm{IIF} 3 * *$ & GU291820 & fusA & $\mathbf{\square}$ & & $\begin{array}{l}\text { R. centenum SW (YP002298082), translation elongation factor, EF-G } \\
\text { (GTPases, COG0480), 0e-0, 62\%, } 78 \%\end{array}$ \\
\hline IIE6 & GU291819 & melA & - & & $\begin{array}{l}\text { Rhodopseudomonas palustris CGA009 (NP945731), } \alpha \text {-D-galactoside } \\
\text { galactohydrolase, melibiase (EC 3.2.1.22), 9e-177, 70\%, } 81 \%\end{array}$ \\
\hline IID7 & GU291848 & eutB & - & & $\begin{array}{l}\text { Bradyrhizobium sp. BTAi1(YP001239723), ethanolamine ammonia-lyase } \\
\text { heavy chain EutB, 0e0, 78\%, 86\% }\end{array}$ \\
\hline IIG4** & GU291849 & $c c p$ & $\mathbf{\square}$ & & $\begin{array}{l}\text { Magnetospirillum gryphiswaldense MSR-1 (CAM76415), cytochrome c551 } \\
\text { peroxidase Ccp, } 1 \mathrm{e}-156,77 \%, 88 \%\end{array}$ \\
\hline $\mathrm{IB} 1 * *$ & GU291804 & $c c p$ & $\mathbf{\square} \mathbf{\square}$ & & $\begin{array}{l}\text { M. gryphiswaldense MSR-1 (CAM76415), cytochrome c551 peroxidase } \\
\text { Ccp, } 1 \mathrm{e}-156,77 \%, 88 \%\end{array}$ \\
\hline IIA4 & GU291811 & $p p k$ & $\boldsymbol{\square}$ & & $\begin{array}{l}\text { Rhodospirillum centenum SW (YP002297760), polyphosphate kinase PPK } \\
\text { (EC2.7.4.1), 0e-0,77\%, 89\% }\end{array}$ \\
\hline IIG6 & GU291824 & $\operatorname{mau} G$ & 口 & & $\begin{array}{l}\text { Pseudovibrio sp. JE062 (ZP05083047), Di-haem cytochrome c peroxidase } \\
\text { (COG1858), family Ccp, 3e-125, 61\%, 73\% }\end{array}$ \\
\hline IF10 & GU291807 & $\operatorname{cox} L$ & $\mathbf{\square}$ & & $\begin{array}{l}\alpha \text {-Proteobacterium BAL199 (ZP02189787), carbon-monoxide } \\
\text { dehydrogenase CoxL (acceptor, EC1.2.99.2), 0e0, 56\%, 70\% }\end{array}$ \\
\hline IE7 & GU291844 & $u v r D$ & $\mathbf{\square} \mathbf{\square}$ & & $\begin{array}{l}\text { M. gryphiswaldense MSR-1 (CAM76107), DNA helicase II (COG0210), } \\
\text { 0e- } 0,64 \%, 76 \%\end{array}$ \\
\hline IIIC6* & GU291829 & $\operatorname{acn} A$ & & $\boldsymbol{\square}$ & $\begin{array}{l}\text { R. centenum SW (YP002299535), aconitate hydratase AcnA (EC4.2.1.3), } \\
\text { 0e } 0,76 \%, 85 \%\end{array}$ \\
\hline IIIF2* & GU291832 & $\operatorname{acn} A$ & & $\mathbf{\square}$ & $\begin{array}{l}\text { R. centenum SW (YP002299535), aconitate hydratase AcnA (EC4.2.1.3), } \\
\text { 0e0,76\%, 85\% }\end{array}$ \\
\hline IIIA8 & GU291845 & maeB & & $\boldsymbol{\square}$ & $\begin{array}{l}\text { R. centenum SW (YP002296658), NAD-dependent malic enzyme (EC } \\
1.1 .1 .40), 0 \mathrm{e} 0,64 \%, 79 \%\end{array}$ \\
\hline IIID1 & GU291830 & $\operatorname{cox} B$ & & $\mathbf{\square} \mathbf{\square}$ & $\begin{array}{l}\text { R. centenum SW (YP002299791), cytochrome c oxidase subunit II CoxB } \\
\text { (EC1.9.3.1), 2e-86, 65\%, 78\% }\end{array}$ \\
\hline IIIC1 & GU291828 & Butanoate metabolism & & घn & $\begin{array}{l}\text { Ochrobactrum intermedium LMG } 3301 \text { (ZP04682997), enoyl-CoA } \\
\text { hydratase/isomerase, crotonase (EC4.2.1.55), 2e-112, 78\%, 88\% }\end{array}$ \\
\hline \multicolumn{6}{|c|}{ Class III: post-translational modifications and proteasome } \\
\hline IIF5 & GU291821 & Proteolysis & $\mathbf{\square}$ & & $\begin{array}{l}\text { Aurantimonas sp. SI85-9A1 (ZP01228661), peptidase M20/M25/M40 } \\
\text { family (EC 3.4.13.20), 1e-138, 57\%, 70\% }\end{array}$ \\
\hline IIH4 & GU291825 & Serralysin & - & & $\begin{array}{l}\text { Azospirillum brasilense (AAS83088), putative protease-like protein, } \\
\text { serralysin family (EC } 3.4 .24 .40), 1 \mathrm{e}-68,36 \%, 48 \%\end{array}$ \\
\hline IA9* & GU291803 & Chaperonin & $\mathbf{\square}$ & & $\begin{array}{l}\text { R. centenum SW (YP002296874), putative DnaJ-like protein DjlA, 3e-66, } \\
57 \%, 72 \%\end{array}$ \\
\hline IB12* & GU291805 & Chaperonin & $\mathbf{\square}$ & & $\begin{array}{l}\text { R. centenum SW (YP002296874), putative DnaJ-like protein Dj1A, 3e-66, } \\
57 \%, 72 \%\end{array}$ \\
\hline \multirow[t]{2}{*}{ IIIH7 } & GU291838 & map & & $\mathbf{\square}$ & $\begin{array}{l}\text { M. magnetotacticum MS-1 (ZP00055468), methionine aminopeptidase, } \\
\text { peptidase M Map (EC 3.4.11.18, COG0024), 1e-117, 75\%, } 85 \%\end{array}$ \\
\hline & & & & & (continued on next page) \\
\hline
\end{tabular}

\footnotetext{
${ }^{\mathrm{x}}$ Induction levels at DAPG trapping concentration of DFI clones assessed in microtiter plates at the corresponding promoter-trapping DAPG concentrations are indicated by black squares $\mathbf{\square}=$ level higher than $3 ; \mathbf{\square}=$ level between 3 and 1.5 ; and $\mathbf{\square}=$ level between 1.5 and 1.3 .

y Asterisks: $*$ identical clone isolated more than one time and $* *=$ clones with a distinct insert for the same gene.

${ }^{\mathrm{z}}$ Organism (accession number), function, levels of significance $=$ E-value, identity, and similarity for the most similar protein sequence.
} 
Of the 96 DFI clones sequenced, 44 were within putative ORF or in the opposite direction of predicted genes, as found in all promoter trap studies (Rediers et al. 2005), and were discarded. These cryptic fusions are attributed to incomplete genome annotations (Silby et al. 2004). Considering the high number of antisense transcripts identified in this and comparable studies, they are unlikely to be artifacts. Rather, they are thought to downregulate gene expression (Rediers et al. 2005; Silby and Levy 2004). Although this approach surveys only a fraction of the upregulated genes (illustrated here with nirK), results clearly indicated that the 52 correctly oriented promoters upregulated by DAPG corresponded to very different cell functions (Table 2), meaning that the DAPG signal may have a broad impact on Azospirillum ecology, as follows.

First, several genes identified are involved in stress response, which may be important to prepare Azospirillum cells located in the immediate vicinity of Pseudomonas DAPG producers for subsequent build-up of DAPG concentration, the compound being inhibitory at high concentration (Cronin et al. 1997; Keel et al. 1992), including for Sp245-Rif. Among those genes, eutB (clone IID7) is involved in the recycling of membrane components (Stojiljkovic et al. 1995), which might be important to counteract negative effects of concentrated DAPG on Azospirillum plasma membrane and cell viability (our

Table 2. (continued from preceding page)

\begin{tabular}{|c|c|c|c|c|c|}
\hline \multirow[b]{2}{*}{ Clone $^{y}$} & \multirow[b]{2}{*}{ Accession no. } & \multirow[b]{2}{*}{ Gene, function } & \multicolumn{2}{|c|}{ Induction level $^{\mathrm{x}}$} & \multirow[b]{2}{*}{ Comparison with closest database sequence ${ }^{\mathrm{z}}$} \\
\hline & & & $0.01 \mu \mathrm{M}$ & $10 \mu \mathrm{M}$ & \\
\hline IIIC8 & GU291833 & lolA & & $\mathbf{\square}$ & $\begin{array}{l}\text { R. centenum SW (YP002298972), outer membrane lipoprotein carrier } \\
\text { protein LolA, 2e-59, 61\%,81\% }\end{array}$ \\
\hline IH8 & GU291846 & Stomatin & & $\mathbf{\square}$ & $\begin{array}{l}\text { Xanthomonas campestris pv. campestris B100 (YP001902680), stomatin- } \\
\text { like membrane protein (band } 7 \text { protein family, qmcA homolog, COG0330), } \\
\text { 2e- } 119,65 \%, 81 \%\end{array}$ \\
\hline \multicolumn{6}{|c|}{ Class IV: biotic-interactions } \\
\hline IIA3 & GU291810 & $f \lg E$ & - & & $\begin{array}{l}\text { A. brasilense Sp245 (ABV72264), flagellar hook protein FlgE, 6e-167, } \\
100 \%, 100 \%\end{array}$ \\
\hline IB8 & GU291806 & nifX-nifB & $\mathbf{\theta}$ & & $\begin{array}{l}\text { Rhodopseudomonas palustris BisA53 (YP780140), nitrogen fixation-related } \\
\text { protein (IPR003731), 7e-25, 44\%, } 72 \%\end{array}$ \\
\hline IIIC3 & GU291854 & ppdC & & $\mathbf{\square}$ & $\begin{array}{l}\text { A. brasilense Sp245 (P51852), phenylpyruvate decarboxylase (EC } \\
\text { 4.1.1.74), } 0 \mathrm{e} 0,99 \%, 99 \%\end{array}$ \\
\hline \multicolumn{6}{|c|}{ Class V: transcriptional regulation } \\
\hline IIB3 & GU291851 & AsnC family & $\mathbf{\square}$ & & $\begin{array}{l}\text { Sinorhizobium medicae WSM419 (YP001327273), AsnC family putative } \\
\text { transcriptional regulator, } 1 \mathrm{e}-55,65 \%, 83 \%\end{array}$ \\
\hline IIC8 & GU291816 & GntR family & $\mathbf{\square}$ & & $\begin{array}{l}\text { M. gryphiswaldense MSR-1 (CAM77897), GntR family transcriptional } \\
\text { regulator, 1e- } 49,55 \%, 68 \%\end{array}$ \\
\hline IF11 & GU291808 & AlgH family & $\mathbf{\square}$ & & $\begin{array}{l}\text { Rhodospirillum centenum SW (YP002299806), AlgH family putative } \\
\text { transcriptional regulator (COG1678), 2e-76, 74\%, } 85 \%\end{array}$ \\
\hline IB4 & GU291839 & Regulator & $\mathbf{\square} \mathbf{a}$ & & $\begin{array}{l}\text { Rhodopseudomonas palustris BisA53 (YP780132), anti- } \sigma \text {-factor antagonist, } \\
\text { STAS domain (COG1366), } 7 \mathrm{e}-14,41 \%, 61 \%\end{array}$ \\
\hline IIIE2 & GU291834 & XRE family & & 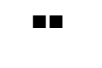 & $\begin{array}{l}\text { Rhodospirillum rubrum ATCC } 11170 \text { (YP427129), XRE family } \\
\text { transcriptional regulator with cupin sensor domain, 1e-67, 69\%, } 81 \%\end{array}$ \\
\hline \multicolumn{6}{|c|}{ Class VI: stimulus perception and signaling } \\
\hline IIIE5 & GU291835 & Response regulator & & $\mathbf{\square}$ & $\begin{array}{l}\text { R. centenum SW (AAP22932), hybrid sensor kinase/response regulator } \\
\text { CstS1 (COG0784, REC superfamily), 5e-11,35\%,54\% }\end{array}$ \\
\hline IIIH5 & GU291837 & Cyclic nucleotide biosynthesis & & $\mathbf{\square}$ & $\begin{array}{l}\text { Bradyrhizobium sp. ORS278 (YP001206407), putative adenylate/guanylate } \\
\text { cyclase (EC4.6.1.1, COG2114), 1e-98, 46\%,62\% }\end{array}$ \\
\hline \multicolumn{6}{|c|}{ Class VII: others } \\
\hline IIF6 & GU291822 & Function unknown & - & & Protein of unknown function, no significant similarity \\
\hline IIC6 & GU291847 & Function unknown & घ & & $\begin{array}{l}\text { Vibrio splendidus 12B01 (ZP00990141), exported protein of unknown } \\
\text { function (COG0303), 1e-06, 37\%, 58\% }\end{array}$ \\
\hline IIG5 & GU291823 & Function unknown & $\mathbf{\square}$ & & $\begin{array}{l}\text { R. rubrum ATCC } 11170 \text { (YP425862), hypothetical protein Rru_A0771, 2e- } \\
118,27 \%, 42 \%\end{array}$ \\
\hline IIH7 & GU291826 & Siderophore biosynthesis & - & & $\begin{array}{l}\text { R. centenum SW (YP002299259) conserved protein of unknown function } \\
\text { (COG4321, predicted arylsulfate sulfotransferase-related proteins), } 4 \mathrm{e}-16 \text {, } \\
45 \%, 62 \%\end{array}$ \\
\hline IIB7 & GU291814 & Putative nuclease & - & & $\begin{array}{l}\text { R. centenum SW (YP002298514), conserved protein of unknown function } \\
\text { with a DUF820 domain (COG4636, PF05685, predicted nucleases), 1e-30, } \\
44 \%, 58 \% \text {. }\end{array}$ \\
\hline $\mathrm{IIC} 4$ & GU291815 & Signal transduction system & $\mathbf{\square}$ & & $\begin{array}{l}\text { M. magneticum AMB-1 (YP420955), CBS domain-containing protein } \\
\text { (PF0057), 2e-24, 45\%, 65\% }\end{array}$ \\
\hline IE12 & GU291852 & Function unknown & $\mathbf{\square}$ & & Protein of unknown function, no significant similarity \\
\hline IC12 & GU291853 & Function unknown & $\mathbf{m}$ & & Protein of unknown function, no significant similarity \\
\hline ID8 & GU291841 & Function unknown & $\mathbf{m}$ & & Protein of unknown function, no significant similarity \\
\hline IH7 & GU291809 & Function unknown & $\mathbf{\square}$ & & Protein of unknown function, no significant similarity \\
\hline IB5 & GU291840 & Function unknown & ma & & Protein of unknown function, no significant similarity \\
\hline IE $1^{*}$ & GU291842 & Signal transduction system & $\mathbf{v} \mathbf{v}$ & & $\begin{array}{l}\text { Ruegeria pomeroyi DSS-3 (YP166747), uncharacterized conserved protein } \\
\text { GfdT (FIST and FIST_C superfamilies), 2e- } 89,48 \%, 63 \%\end{array}$ \\
\hline IE3* & GU291843 & Signal transduction system & ma & & $\begin{array}{l}\text { R. pomeroyi DSS-3 (YP166747), uncharacterized conserved protein GfdT } \\
\text { (FIST and FIST_C superfamilies), 2e- } 89,48 \%, 63 \%\end{array}$ \\
\hline IIIG1 & GU291850 & Function unknown & & - & Protein of unknown function, no significant similarity \\
\hline IIID6 & GU291831 & Putative signaling protein & & $\mathbf{\square}$ & $\begin{array}{l}\text { Labrenzia alexandrii DFL-11 (YP002613697), conserved hypothetical } \\
\text { protein with a PDZ domain (IPR001478) }\end{array}$ \\
\hline IIIG6 & GU291836 & Siderophore biosynthesis & & - & $\begin{array}{l}\text { a-Proteobacterium BAL199 (ZP02186779), hypothetical protein } \\
\text { (COG4321, predicted arylsulfate sulfotransferase-related proteins), 8e-11, } \\
50 \%, 73 \%\end{array}$ \\
\hline
\end{tabular}


A

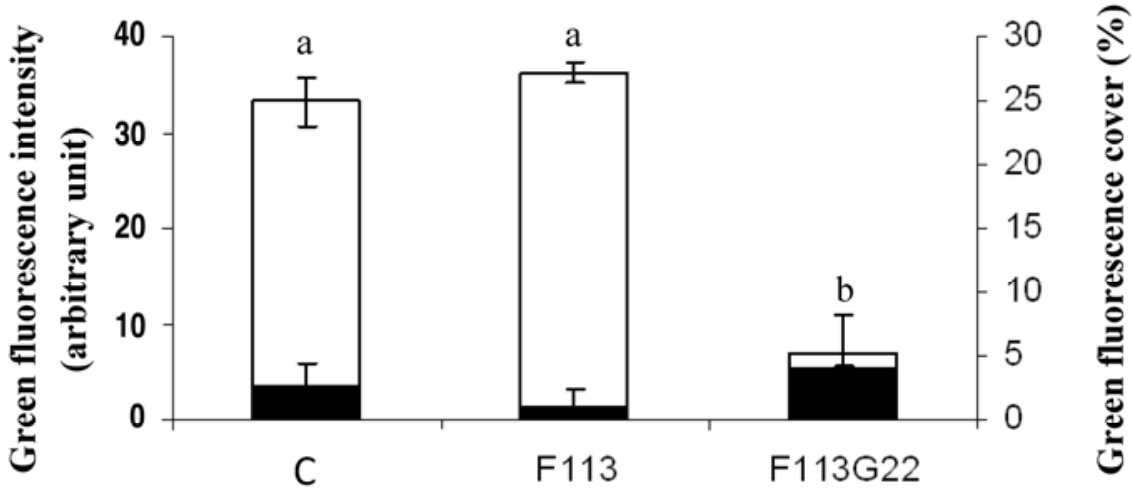

B

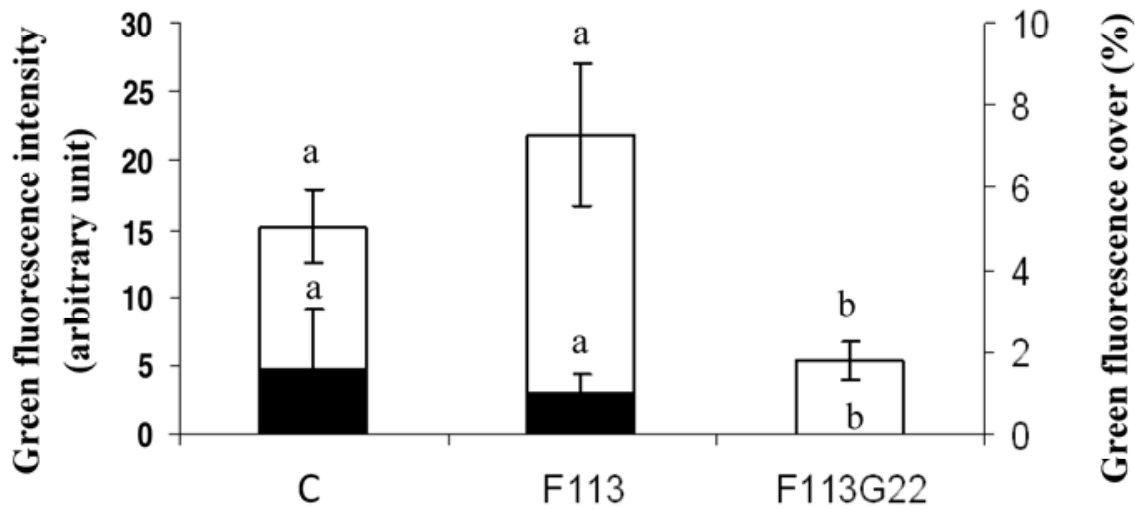

C

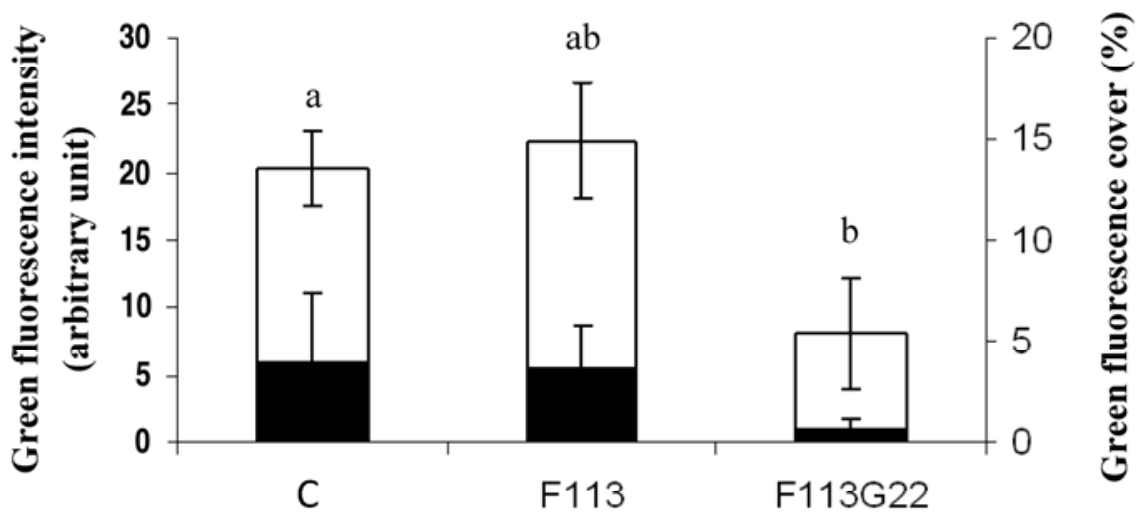

D

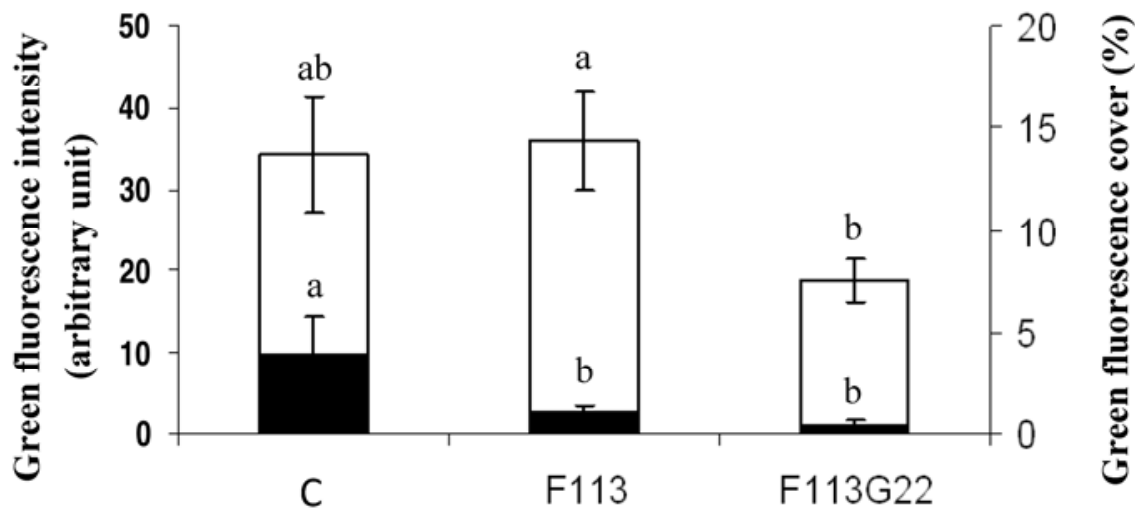

Fig. 5. Semiquantitative analysis of in planta fluorescence levels of Azospirillum brasilense Sp245-Rif differential fluorescence induction (DFI) clones expressing the A, nirK-egfp; B, flgE-egfp; C, nifX-nifB-egfp; and D, ppdC-egfp fusions on wheat after single inoculation (C), and coinoculations in the presence of Pseudomonas fluorescens F113 or its phl-negative derivative F113G22. For each DFI clone, confocal images were acquired using the same detector amplification gain to allow semiquantitative comparison of fluorescence between treatments. The bioImage_L software 1.0 was used to quantify the threshold level of green fluorescence intensity in the analyzed images (white bars) and the percentage of the area covered by green fluorescent cells (black bars). For each treatment, means were calculated from one or two images per root system, and at least three independent root systems were considered. Data are expressed as the means \pm standard deviation ( $n=3$ to 6$)$. Letters indicate significant differences among treatments $(P<0.05$, Kruskal-Wallis paired comparison). For DFI clones expressing the nirK-egfp and nifX-nifB-egfp fusions, green fluorescence cover percents were not significantly different between treatments. 
transmission electronic microscopy data, unpublished). DAPG is known to cause plasma membrane disorganization also in fungi (de Souza et al. 2003). Whether DAPG can damage other cell components in strain Sp245-Rif is not known but DAPG upregulation of genes encoding proteases (IIIH7, IIF5, and IIH4), a predicted nuclease (IIB7), and a UvrD helicase (IE7) means it could be the case. Alternatively, DAPG upregulation of these genes is perhaps useful to counteract stress conditions expected in the rhizosphere (Miché and Balandreau 2001). With regard to this hypothesis, DAPG induces DFI clone IIIC1 (Table 2), which encodes an enoyl-CoA hydratase/isomerase potentially involved in PHB biosynthesis (Fiedler et al. 2002). PHB accumulation, which increased linearly with DAPG concentrations (Fig. 3), favors A. brasilense survival under stress conditions (Kadouri et al. 2003; Kamnev et al. 2008). PHB production was probably fueled by consumption of the culture medium carbon source (malate), because malate utilization genes maeB and $a c n A$ were induced by DAPG. Accordingly, these three genes were induced at the higher DAPG concentration tested. It is worth noting that genes homologous to hydrolase-encoding $p h l G$, so far the only bacterial gene known to be involved in DAPG resistance (in Pseudomonas strain CHA0) (Bottiglieri and Keel 2006), are not present in the Sp245-Rif genome but another unknown resistance mechanism might be involved in this strain.

Second, one DFI clone (IIA3) was the flagellar hook protein gene $f l g E$ and exemplifies genes involved in Azospirillum spp. establishment in the rhizosphere. DAPG upregulation of this gene was confirmed at DAPG concentrations of both 0.01 and $10 \mu \mathrm{M}$ (data not shown) and correlated with enhanced motility (Fig. 1). In Azospirillum spp., the polar flagellum is required for motility toward the root (Croes et al. 1993) and mediates the initial steps of cell adsorption to the root surface and of biofilm formation (Turnbull et al. 2001; Zamudio and Bastarrachea 1994). Accordingly, the ability of Sp245-Rif to form biofilm increased with DAPG concentrations (Fig. 2). Consistent with this, ppk (clone IIA4), which also contributes to cell motility and biofilm formation (Brown and Kornberg 2008; Daniels et al. 2004), was upregulated by DAPG.

Third, DAPG induced Sp245-Rif genes potentially involved in sensing rhizosphere constituents. liv $G$ (strongly upregulated by $10 \mu \mathrm{M}$ DAPG) codes an ABC transporter for branched-chain amino acids, whose supply by legumes regulates the symbiosis with Rhizobium spp. (Prell et al. 2009). Moreover, several DAPG-induced genes (i.e., $c c p, \operatorname{cox} B, \operatorname{cox} L$, and $m a u G$ ) are involved in electron transfer and might play a key role in energy taxis response, which promotes root colonization by $A$. brasilense (Alexandre et al. 2004; Greer-Phillips et al. 2004).

Fourth, DAPG induced genes involved in plant growth promotion, such as $p p d C$ (IIIC3; IAA production), nirK (DFI-32; nitric oxide production), and nifX-nifB (IB8; nitrogen fixation). DAPG upregulation of $p p d C$ was confirmed by further in vitro analysis of $p p d C$ gene expression and production of IAA in the presence of increasing concentrations of DAPG (Fig. 4). DAPG can also stimulate lateral root production by interacting with the plant auxin pathway in tomato (Brazelton et al. 2008), which means that DAPG-mediated phytostimulation might involve both a direct effect on the plant and an indirect effect via Azospirillum IAA production. The NirK denitrification product nitric oxide is another signal molecule stimulating lateral root formation (Creus et al. 2005; Molina-Favero et al. 2008), whose effects on the plant are expected to add up to those of IAA. DAPG also enhanced the expression of genes nif $X$-nif $B$ involved in nitrogen fixation, which is interesting because nitrogen fixation has often been portrayed as a plantbeneficial trait of less importance in Azospirillum spp. (Barbieri et al. 1986; Dobbelaere et al. 2003).
On roots, the enhanced expression of Sp245-Rif genes important for phytostimulation in the presence of F113 compared with its $p h l$-negative mutant was confirmed. Confocal analysis showed that $n i r K, p p d C$, flgE, and nifX-nifB were highly induced in the presence of the DAPG-producing Pseudomonas strain. The enhanced green protein fluorescence on confocal images from DFI clones inoculated with F113 was not due to an increase in the number and size of Azospirillum cells but, clearly, to the induction of the expression of these Azospirillum genes by the DAPG-producing Pseudomonas strain. These genes were already expressed when Azospirillum spp. were alone on wheat roots (Fig. 5), raising the possibility that plant signals may act in synergy with DAPG to activate the expression of Sp245-Rif genes important for phytostimulation. In the presence of the $p h l$-negative mutant, the expression of the four genes was strongly decreased. Inactivation of DAPG production in F113 may have reduced the plant-beneficial activity of Azospirillum spp. without altering their culturability, such as by enhancing the production of the Pseudomonas secondary metabolite hydrogen cyanide. Thus, DAPG may alleviate the downregulation of Azospirillum genes observed with the mutant strain. The possibility cannot be excluded that the distinct effects of F113 and F133G22 on Azospirillum gene transcription might involve indirect effects of Pseudomonas strains through modifications of plant host physiology. The comparison of the influence of the Pseudomonas DAPG producer versus its phlnegative mutant on Azospirillum-mediated effects on plant growth suggests that DAPG enhances Azospirillum plantgrowth promoting activities. From these observations, it is tempting to speculate that DAPG has become a signal for beneficial plant-microbe interactions during co-evolution of plants with its guild of PGPR partners.

\section{MATERIALS AND METHODS}

\section{Bacterial strains and media.}

Bacterial strains and plasmids are listed in Table 3. A. brasilense was grown at $28^{\circ} \mathrm{C}$ in Luria-Bertani medium (Sambrook et al. 1989) containing $\mathrm{NaCl}$ at only $5 \mathrm{~g} \mathrm{liter}^{-1}$ (i.e., $\mathrm{LBm}$ ), $\mathrm{AB}$ medium (Chilton et al. 1974) containing malic acid at $5 \mathrm{~g}$ liter ${ }^{1}$ as carbon source (i.e., ABmal), or Nfb (Nelson and Knowles 1978) supplemented with $1 / 40$ ( $\mathrm{vol} / \mathrm{vol}$ ) $\mathrm{LBm}$ (i.e., $\mathrm{Nfb}^{*}$ ). $P$. fluorescens strains were grown at $28^{\circ} \mathrm{C}$ in sucrose asparagine iron medium (i.e., SA-Fe) (Cronin et al. 1997). Liquid cultures were incubated on a rotary shaker at $50 \mathrm{rpm}$ (for microtiter plates) or $180 \mathrm{rpm}$. Only one-third of the tubes were filled to ensure fully aerobic conditions. Antibiotics (Euromedex, Souffelweyersheim, France) were added at the following final concentrations: ampicillin (Ap), $100 \mu \mathrm{g} \mathrm{ml} \mathrm{m}^{-1}$; chloramphenicol $(\mathrm{Cm}), 30 \mu \mathrm{g} \mathrm{ml}^{-1}$; gentamicin $(\mathrm{Gm}), 25 \mu \mathrm{g} \mathrm{ml}^{-1}$; and rifampicin (Rif), $50 \mu \mathrm{g} \mathrm{ml}^{-1}$.

\section{Effect of synthetic DAPG on adhesion and motility of $A$. brasilense Sp245-Rif.}

The effect of synthetic DAPG (Toronto Research Chemicals Inc., North York, Canada) on adhesion of $A$. brasilense Sp245-Rif to polystyrene was investigated in 24-well microtiter plates (Nalgene NUNC, Roskilde, Denmark). DAPG was dissolved in methanol (from 0.0001 to $1 \mathrm{mM}$ DAPG) and $15 \mu \mathrm{l}$ was added to $1.5 \mathrm{ml}$ of ABmal medium in each well. Methanol (1\% vol/vol) was used as DAPG-negative control. Sp245-Rif was inoculated at $1.5 \times 10^{6}$ cells $\mathrm{ml}^{-1}$ by adding aliquots from a 48-h $\mathrm{Nfb}^{*}$ culture. The effect of DAPG concentrations (from 0.001 to $10 \mu \mathrm{M}$ DAPG) was analyzed twice using independent Sp245-Rif cell cultures and four replicates per treatment $(n=8)$. The microtiter 
plates were incubated 6 days at $28^{\circ} \mathrm{C}$, and biofilm formation was measured as described by Dorel and associates (1999). Briefly, the liquid medium (and the planktonic bacteria it contained) was carefully removed using a pipette. Biofilms developed on polystyrene surfaces were gently washed off using $500 \mu \mathrm{l}$ of $\mathrm{ABm}$ medium, and biofilm bacteria were suspended in $1.5 \mathrm{ml}$ of cold $\mathrm{ABm}$ medium by pipetting up and down. In both samples (planktonic bacteria and biofilm bacteria), cell numbers were estimated by measuring the optical density at $600 \mathrm{~nm}\left(\mathrm{OD}_{600}\right)$. Adhesion was computed as the ratio between biofilm bacteria and total bacteria.

The effect of synthetic DAPG on motility of A. brasilense Sp245-Rif was assessed on soft agar LBm plates containing $0.2 \%$ (swimming ability) or $0.7 \%$ (swarming ability) noble agar (Difco Laboratories, Detroit) and 0.001 to $100 \mu \mathrm{M}$ DAPG. Methanol (1\% vol/vol) was used as a DAPG-negative control. Strain Sp245-Rif was inoculated at $1 \times 10^{7}$ cells by adding $5 \mu$ of overnight $\mathrm{LBm}$ culture on top of the plates. The plates were incubated for 3 days face up at $28^{\circ} \mathrm{C}$; then, diameters of motility halos were measured. The analysis was done twice using independent Sp245-Rif cell cultures, with three replicates per treatment $(n=6)$.

\section{Effect of synthetic DAPG}

on PHB accumulation by $A$. brasilense Sp245-Rif.

The impact of $1 \%(\mathrm{vol} / \mathrm{vol})$ methanol (DAPG-negative control) and DAPG (0.001 to $100 \mu \mathrm{M})$ on PHB accumulation inside intact cells of $A$. brasilense Sp245-Rif was evaluated by staining cells with Nile Red, as described by Degelau and associates (1995). For all staining assays, Nile Red $\left(1 \mathrm{mg} \mathrm{ml}^{-1}\right)$ was prepared in acetone. Planktonic Sp245-Rif cells (obtained as described above) were diluted in phosphate buffer saline (PBS) to reach $10^{6}$ cells $\mathrm{ml}^{-1}$, based on $\mathrm{OD}_{600}$ measurements. An aliquot of $0.5 \mathrm{ml}$ of $\mathrm{Sp} 245$-Rif bacterial suspension was mixed with $0.5 \mathrm{ml}$ of cold absolute ethanol and $10 \mu \mathrm{l}$ of Nile Red solution. The mixture was incubated for 30 to $40 \mathrm{~min}$ at room temperature. Because fluorescence signals are proportional to cell PHB content (Degelau et al. 1995), red fluorescence level was quantified by flow cytometry, using a FACSCanto II (Becton Dickinson Biosciences, Pont de Claix, France) fitted with a HeNe laser emitting at $633 \mathrm{~nm}$ and with an allophycocyanin filter for emission. FACSDiva and WinMDI software were used for acquisition and parameter analysis, respectively.

\section{Effect of synthetic DAPG}

on IAA production ability of $A$. brasilense Sp245-Rif.

To assess the effect of synthetic DAPG on IAA production ability of $A$. brasilense Sp245-Rif(pOT1e-ppdC-egfp) (i.e., DFI clone IIIC3), the strain was grown in $1.5 \mathrm{ml}$ of ABmal (in 24-well microtiter plates) supplemented with tryptophan at $100 \mu \mathrm{g} \mathrm{ml}^{-1}$ and either $1 \%$ (vol/vol) methanol (DAPG-negative control) or DAPG $(0.001$ to $10 \mu \mathrm{M})$. The plates were incubated for 6 days at $28^{\circ} \mathrm{C}$ and cell density was estimated based on $\mathrm{OD}_{600}$ measurements. IAA production ability was investigated at two complementary levels. First, the enhanced green protein fluorescence of the $p p d C$-egfp fusion was measured in $150 \mu \mathrm{l}$ of each culture, using a Xenius spectrofluorimeter microtiter plate reader (Safas, Monaco, France) (excitation at $488 \mathrm{~nm}$, emission at $510 \mathrm{~nm}$, wavelength slit of $10 \mathrm{~nm}$ ). Second, $100 \mu \mathrm{l}$ of each culture was removed and centrifuged, and the supernatant was assayed for the presence of IAA and related indole compounds using the PC Salkowski colorimetric method as described by Glickmann and Dessaux (1995).

\section{Promoter trapping of A. brasilense Sp245-Rif genes induced by synthetic DAPG.}

DFI and flow cytometry cell sorting were used to screen the egfp promoter-trap library PTL-AbP (Pothier et al. 2007) and identify DAPG-inducible promoters in A. brasilense Sp245Rif. The library, with 96,000 clones, represents nearly a threefold coverage of the Sp245 genome, and the representativeness of the A. brasilense Sp245-Rif promoter-trap library was significant (Pothier et al. 2007).

Ap, Rif, and Gm were added to all growth media used afterward. An aliquot $(25 \mu \mathrm{l})$ from the PTL-AbP library was used to inoculate $5 \mathrm{ml}$ of $\mathrm{ABmal}$ medium. After an 8 -h incubation (i.e., until exponential phase), $250 \mu$ were transferred to $25 \mathrm{ml}$ of ABmal medium supplemented with 0.01 or $10 \mu \mathrm{M}$ DAPG. Cells were incubated for $40 \mathrm{~h}$ (i.e., until stationary phase) and

Table 3. Bacterial strains, plasmids, and libraries used in this study

\begin{tabular}{|c|c|c|}
\hline Strains, plasmids and library & Description $^{\mathrm{z}}$ & Reference or source \\
\hline \multicolumn{3}{|l|}{ Strains } \\
\hline Azospirillum brasilense Sp245-Rif & Root-proficient, spontaneous rifampicin-resistant mutant of Sp245 & Pothier et al. 2007 \\
\hline Sp245-Rif(pR2.54) & $\begin{array}{l}\text { DFI clone DFI-32 (i.e., Sp245-Rif strain containing PnirK-egfp transcription fusion } \\
\text { in pOT1e; } \mathrm{Gm}^{\mathrm{r}} \text { ) }\end{array}$ & Pothier et al. 2007 \\
\hline Sp245-Rif(pOT1e-soxR-egfp) & $\begin{array}{l}\text { Positive fluorescent control strain for the establishment of flow cytometry } \\
\text { parameters }\end{array}$ & Pothier et al. 2007 \\
\hline Sp245-Rif(pOT1e-flgE-egfp) & $\begin{array}{l}\text { DFI clone IIA3 (i.e., Sp245-Rif strain containing PflgE-egfp transcription fusion in } \\
\text { pOT1e; } \mathrm{Gm}^{\mathrm{r}} \text { ) }\end{array}$ & This study \\
\hline Sp245-Rif(pOT1e-nifX-egfp) & $\begin{array}{l}\text { DFI clone IB8 (i.e., Sp245-Rif strain containing PnifX-egfp transcription fusion in } \\
\text { pOT1e; } \mathrm{Gm}^{\mathrm{r}} \text { ) }\end{array}$ & This study \\
\hline Sp245-Rif(pOT1e-ppdC-egfp) & $\begin{array}{l}\text { DFI clone IIIC3 (i.e., Sp245-Rif strain containing PppdC-egfp transcription fusion in } \\
\text { pOT1e; Gm }{ }^{\text {r }} \text { ) }\end{array}$ & This study \\
\hline Pseudomonas fluorescens $\mathrm{F} 113$ & Strain isolated from sugar beet & Shanahan et al. 1992 \\
\hline P. fluorescens $\mathrm{F} 113 \mathrm{G} 22$ & F113 derivative, with a Tn $5:: l a c Z Y$ insertion in $p h l$ operon, $\mathrm{Km}^{\mathrm{r}}$ & Shanahan et al. 1992 \\
\hline Escherichia coli $\mathrm{DH} 5 \alpha$ & 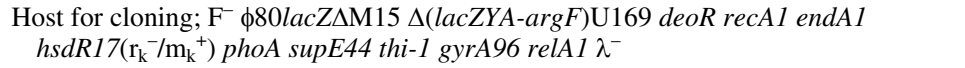 & Invitrogen \\
\hline E. coli $\mathrm{S} 17.1 \lambda$ pir & $\begin{array}{l}\text { Host for conjugal plasmid transfer; recA endA thi pro hsdRM }{ }^{+} \Omega R P 4-2-\mathrm{Tc}:: \mathrm{Mu}- \\
\mathrm{Km}:: \operatorname{Tn} 7 ; \mathrm{Sm}^{\mathrm{r}} \mathrm{Tp}^{\mathrm{r}}\end{array}$ & de Lorenzo and Timmis 1994 \\
\hline \multicolumn{3}{|c|}{ 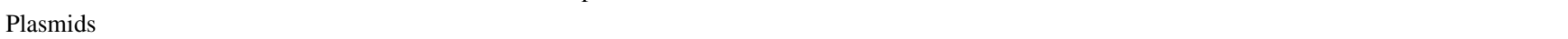 } \\
\hline pOT1e & $\begin{array}{l}\text { Promoter probe vector based on pBBR1MCS- } 5 \text { replicon. Contains promoterless } e g f p \\
\text { and MCS between two transcriptional terminators; } \mathrm{Gm}^{\mathrm{r}}\end{array}$ & Allaway et al. 2001 \\
\hline \multicolumn{3}{|c|}{ 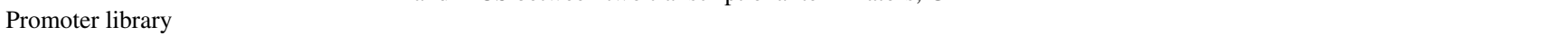 } \\
\hline PTL-AbP & $\begin{array}{l}\text { Promoter trap library in A. brasilense Sp245-Rif containing 1- to 3-kb fragments } \\
\text { upstream egfp in pOT1e }\end{array}$ & Pothier et al. 2007 \\
\hline
\end{tabular}

\footnotetext{
${ }^{\mathrm{z}} \mathrm{Gm}^{\mathrm{r}}, \mathrm{Km}^{\mathrm{r}}, \mathrm{Sm}^{\mathrm{r}}$, and $\mathrm{Tp}^{\mathrm{r}}=$ resistant to gentamicin, kanamycin, streptomycin, and trimethoprim, respectively.
} 
sorted, retaining fluorescent cells. This was done with an FACSVantage SE (Becton Dickinson Biosciences) fitted with a 15-mW argon laser emitting at $488 \mathrm{~nm}$, using the single-cell mode of the apparatus. Sterile $(0.22-\mu \mathrm{m}$ filtered) PBS was used as sheath fluid for analysis and for cell sorting. In total, $10^{7}$ cells were assessed, which ensured full coverage of the PTL-AbP library based on the formula of Daugherty and associates (2000). Prior to cell sorting or analysis, flow cytometry parameters were set using A. brasilense Sp245-Rif(pOT1e) as the nonfluorescent control and one A. brasilense clone, Sp245Rif(pOT1e-soxR-egfp), expressing egfp constitutively as the positive control (Pothier et al. 2007). This resulted in the selection of the 11.7 and $2.31 \%$ most fluorescent cells among the $10^{7}$ cells assessed for the 0.01 and $10 \mu \mathrm{M}$ DAPG conditions, respectively, each of which was gathered into a 5-ml BD Falcon tube (Dickinson Biosciences) and transferred to $20 \mathrm{ml}$ of $\mathrm{ABmal}$ medium. After $40 \mathrm{~h}$ of incubation, the cells were sorted again, retaining nonfluorescent cells (approximately 58 and $4.5 \%$ for 0.01 and $10 \mu \mathrm{M}$ DAPG experiments, respectively), in order to discard constitutive promoters.

For final selection, the sorted cells were transferred to ABmal medium, grown for $40 \mathrm{~h}$, induced again with DAPG at 0.01 or $10 \mu \mathrm{M}$ during $40 \mathrm{~h}$, and sorted. The most fluorescent cells (4.34 and $15.0 \%$ for 0.01 and $10 \mu \mathrm{M}$ DAPG, respectively) were subsequently distributed into wells (in 96-well plates) containing $\mathrm{LBm}$ agar and incubated for 2 days at $28^{\circ} \mathrm{C}$ (filling 20 and 10 microtiter plates for the 0.01 and $10 \mu \mathrm{M}$ DAPG conditions, respectively).

Confirmation of DAPG induction of the clones was sought by incubating each clone in ABmal medium containing $1 \%$ methanol or DAPG $(0.01$ or $10 \mu \mathrm{M}$ depending on DFI condition) for $48 \mathrm{~h}$ and measuring fluorescence using a spectrofluorimeter microtiter plate reader as described above. Fluorescence intensity of sorted clones (i.e., Iabs) and Sp245Rif(pOT1e) control (i.e., Iabc), as well as $\mathrm{OD}_{600}$ of sorted clones (i.e., $\mathrm{OD}_{600} \mathrm{~s}$ ) and Sp245-Rif(pOT1e) control (i.e., $\left.\mathrm{OD}_{600} \mathrm{c}\right)$ were measured, using growth medium as blank. Relative fluorescence intensity (Ir) was calculated based on the formula: $\mathrm{Ir}=\mathrm{Iabs} / \mathrm{OD}_{600} \mathrm{~s}-\mathrm{Iabc} / \mathrm{OD}_{600} \mathrm{c}$. Individual clones showing at least a 1.3 -fold increase in relative fluorescence intensity compared with the methanol condition were selected.

\section{Sequence analysis of Sp245-Rif DFI clones' promoters.}

To characterize DAPG-upregulated Sp245-Rif DFI clones selected by DFI promoter trapping, their inserts were amplified with PCR primers F2603 and F2604 (Pothier et al. 2007). PCR amplifications were performed according to the Taq polymerase manufacturer (Invitrogen, Cergy Pontoise, France). In each reaction tube, $100 \mathrm{ng}$ of template DNA was used in $50 \mu \mathrm{l}$. The amplification cycle consisted of an initial $5 \mathrm{~min}$ at $95^{\circ} \mathrm{C} ; 35$ cycles of $30 \mathrm{~s}$ at $95^{\circ} \mathrm{C}, 30 \mathrm{~s}$ at $55^{\circ} \mathrm{C}$, and $30 \mathrm{~s}$ (or $90 \mathrm{~s}$ for large amplicons) at $72^{\circ} \mathrm{C}$; followed by a final 7 -min extension at $72^{\circ} \mathrm{C}$. For large inserts $(>2 \mathrm{~kb})$, the plasmids were isolated from the DFI clones using the NucleoSpin Plasmid kit (Macherey-Nagel, Hoerdt, France) and were sequenced with primer F2604. Sequencing was performed by Cogenics (Meylan, France) and sequences were analyzed with BLASTN and BLASTX algorithms (Altschul et al. 1997). ORF identification was done with FramePlot 2.3.2 (Ishikawa and Hotta 1999). Preliminary data of the A. brasilense Sp245 genome sequencing project were used for ORF prediction. Sequences obtained in the current work are deposited under GU291803 to GU291854.

\section{In vitro DAPG induction of Sp245-Rif DFI clones.}

The in vitro induction of four Sp245-Rif DFI clones was assessed by spectrofluorimetry analysis of egfp expression, as follows. Each clone was grown for $24 \mathrm{~h}$ in ABmal $\mathrm{Gm}$ Rif medium. Culture aliquots (in volumes containing $1.5 \times 10^{7}$ cells) were transferred to $1.5 \mathrm{ml}$ of fresh ABmal $\mathrm{Gm}$ Rif medium containing $1 \%$ methanol (control), 0.01 or $10 \mu \mathrm{M}$ DAPG, and grown for $48 \mathrm{~h}$ at $28^{\circ} \mathrm{C}$. Strain Sp245-Rif(pOT1e) was used as nonfluorescent control. Quantitative analysis of fluorescence in bacterial cultures $(100 \mu \mathrm{l})$ was done as described above.

\section{In planta induction experiments.}

Seed of spring wheat (Triticum aestivum cv. Fiorina, $10 \mathrm{~g}$ ), obtained from Florimond-Desprez (Cappelle en Pévèle, France), were surface-sterilized as described by Pothier and associates (2007), and germinated on water agar $\left(8 \mathrm{~g} \mathrm{liter}^{-1}\right)$ for 3 days in the dark at $28^{\circ} \mathrm{C}$. The inoculants were obtained by overnight growth in liquid SA-Fe for P. fluorescens F113 and its $p h l$-negative mutant $\mathrm{F} 113 \mathrm{G} 22$ or ABmal $\mathrm{Gm}$ for $A$. brasilense strains. The cells were collected by centrifugation $(6,000 \mathrm{rpm})$, gently washed, and resuspended in $0.8 \% \mathrm{NaCl}$ solution, and the suspensions adjusted (based on $\mathrm{OD}_{600}$ ) to $1 \times$ $10^{7}$ (for Pseudomonas spp.) or $2 \times 10^{8} \mathrm{CFU} \mathrm{ml}^{-1}$ (for Azospirillum spp.). Inoculation of each $A$. brasilense Sp245-Rif DFI clone, alone or 2 days later together with F113 or F113G22, was done by adding $50 \mu \mathrm{l}$ of the corresponding cell suspension per seedling. The same volume of $0.8 \% \mathrm{NaCl}$ solution was added for single inoculations or in the noninoculated control. Square plates (120 by 120 by $17 \mathrm{~mm}$ (Greiner Bio One, Frickenhausen, Germany) containing water agar (8 g liter $^{-1}$ ) and four seedlings were used. The plates were placed vertically for 7 days in a growth chamber at $20^{\circ} \mathrm{C}$ with $16 \mathrm{~h}$ of light $\left(150 \mu \mathrm{E} \mathrm{m}^{-2} \mathrm{~s}^{-1}\right)$ and $8 \mathrm{~h}$ of darkness. Four plants (i.e., two plants from two independent experiments) were studied per treatment.

For confocal laser scanning microscopy, root pieces 1 to $2 \mathrm{~cm}$ in length were mounted in Aqua-Poly/Mount (Polysciences, Eppelheim, Germany) and examined immediately. Semiquantitative comparisons of fluorescence intensities of DFI clones on roots were made using a 510 Meta microscope (Carl Zeiss S.A.S., Oberkochen, Germany) equipped with an argon-krypton laser, detectors, and filter sets for green fluorescence (i.e., $488 \mathrm{~nm}$ for excitation and 510 to $531 \mathrm{~nm}$ for detection). After acquisition of the transmitted image (in bright-field mode), the two single-color images were overlaid as a single image using LSM software (release 3.5; Carl Zeiss S.A.S.). At least two independent root systems were analyzed per treatment and five images per root system, and the whole experiment was done twice. The same detector amplification gains were used for semiquantitative comparison of fluorescence levels. The bioImage_L software 1.0 was used to quantify the threshold level of green fluorescence intensity in the images analyzed and the surface area covered by green fluorescent cells (Chávez de Paz 2009).

\section{Plant-growth promotion assay.}

To assess growth promotion of spring wheat cv. Fiorina by A. brasilense $\mathrm{Sp} 245$-Rif in coinoculation with $P$. fluorescens F113 or F113G22, strain Sp245-Rif was grown overnight in 50 $\mathrm{ml}$ of ABmal medium. Cells were centrifuged and resuspended in $0.8 \% \mathrm{NaCl}$ solution to obtain $10^{9}$ cells $\mathrm{ml}^{-1}$. Then, $5 \times 10^{8}$ Sp245-Rif cells were mixed with $50 \mathrm{ml}$ of water agar $(0.8 \%)$, which was introduced into 120-by-120-by-17-mm square plates. Noninoculated plants were used as control. Four disinfected seeds (as described above) were then laid onto the plates, which were incubated vertically in a growth chamber at $20^{\circ} \mathrm{C}$ with $16 \mathrm{~h}$ of light $\left(150 \mu \mathrm{E} \mathrm{m}^{-2} \mathrm{~s}^{-1}\right)$ and $8 \mathrm{~h}$ of darkness. Then, 2 days later (to avoid any growth inhibition effect of strain Sp245-Rif), $50 \mu$ l containing $10^{6}$ cells of P. fluorescens 
F113 or F113G22 or $50 \mu \mathrm{l}$ of $0.8 \% \mathrm{NaCl}$ were added on seeds. At 7 days, root system architecture was examined by image analysis (WinRHIZO 2002c; Régent Instrument Inc., Québec City, Canada) to quantify total root length, root surface area, average root diameter, total root volume, and root numbers, using at least 20 plants (five plates containing 4 plants) per treatment.

\section{Statistical analysis.}

For PHB contents, the area under the curve of emitted fluorescence $(660 \mathrm{~nm})$ was taken and log transformed, and its relation with DAPG concentration was assessed by linear regression (linear model, $P<0.05$ ) using S-plus software (TIBCO Software Inc., Palo Alto, CA, U.S.A.). Plant and bacterial data were processed by analysis of variance followed, when appropriate, with Fisher's least significant difference tests or by Kruskal-Wallis paired comparison. Stats were done at $P<0.05$, using S-plus software 6.1.

\section{ACKNOWLEDGMENTS}

This work was supported by the Ministère Français de la Recherche and IFR 41 (Université Lyon 1). We thank F. Bellvert, G. Comte, O. Couillerot, H. Sanguin, M.-A. Poirier, and F. Wisniewski-Dyé (UMR CNRS 5557 Ecologie Microbienne, Université Lyon 1) and D. Ressnikoff (Centre Commun Quantimétrie, Université Lyon 1) for technical assistance and helpful discussion; I. Joulin (University of Tennessee) for access to the $A$. brasilense Sp245 draft genome sequence, supported by a US-NSF grant EF-0412186 to I. Joulin; and F. O'Gara (University College Cork, Ireland) for providing the Pseudomonas strain and mutants. This work made use of the technical platforms DTAMB, Serre, and Centre Technologique des Microstructures at IFR 41 (Université Lyon 1).

\section{LITERATURE CITED}

Alexandre, G., Greer-Phillips, S. E., and Zhulin, I. B. 2004. Ecological role of energy taxis in microorganisms. FEMS (Fed. Eur. Microbiol. Soc.) Microbiol. Rev. 28:113-126.

Allaway, D., Schofield, N. A., Leonard, M. E., Gilardoni, L., Finan, T. M., and Poole, P. S. 2001. Use of differential fluorescence induction and optical trapping to isolate environmentally induced genes. Environ. Microbiol. 3:397-406.

Altschul, S. F., Madden, T. L., Schaffer, A. A., Zhang, J. H., Zhang, Z., Miller, W., and Lipman, D. J. 1997. Gapped BLAST and PSI-BLAST: A new generation of protein database search programs. Nucleic Acids Res. 25:3389-3402.

Baehler, E., Bottiglieri, M., Péchy-Tarr, M., Maurhofer, M., and Keel, C. 2005. Use of green fluorescent protein-based reporters to monitor balanced production of antifungal compounds in the biocontrol agent Pseudomonas fluorescens CHA0. J. Appl. Microbiol. 99:24-38.

Bais, H. P., Weir, T. L., Perry, L. G., Gilroy, S., and Vivanco, J. M. 2006. The role of root exudates in rhizosphere interations with plants and other organisms. Annu. Rev. Plant Biol. 57:233-266.

Bakker, P. A. H. M., Pieterse, C. M. J., and van Loon, L. C. 2007. Induced systemic resistance by fluorescent Pseudomonas spp. Phytopathology 97:239-243

Bally, R., and Elmerich, C. 2007. Biocontrol of plant diseases by associative and endophytic nitrogen-fixing bacteria. Pages 171-190 in: Associative and Endophytic Nitrogen-Fixing Bacteria and Cyanobacterial Associations. C. Elmerich and W. E. Newton, eds. Kluwer Academic Publishers, Dordrecht, The Netherlands.

Barbieri, P., Zanelli, T., Galli E., and Zanetti G. 1986. Wheat inoculation with Azospirillum brasilense Sp6 and some mutants altered in nitrogen fixation and indole-3-acetic acid production. FEMS (Fed. Eur. Microbiol. Soc.) Microbiol. Lett. 36:87-90.

Bashan, Y., and de-Bashan, L. E. 2002. Protection of tomato seedlings against infection by Pseudomonas syringae pv. tomato by using the plant growth-promoting bacterium Azospirillum brasilense. Appl. Environ. Microbiol. 68:2637-2643.

Bjørnlund, L. B., Mork, S., Vestergard, M., and Ronn, R. 2006. Trophic interactions between rhizosphere bacteria and bacterial feeders influenced by phosphate and aphids in barley. Biol. Fertil. Soil. 43:1-11.

Bonsall, R. F., Weller, D. M., and Thomashow, L. S. 1997. Quantification of 2,4-diacetylphloroglucinol produced by fluorescent Pseudomonas spp. in vitro and in the rhizosphere of wheat. Appl. Environ. Microbiol.
63:951-955.

Bottiglieri, M., and Keel, C. 2006. Characterization of PhlG, a hydrolase that specifically degrades the antifungal compound 2,4-diacetylphloroglucinol in the biocontrol agent Pseudomonas fluorescens CHA0. Appl. Environ. Microbiol. 72:418-427.

Bouwmeester, H. J., Roux, C., López-Ráez, J. A., and Bécard, G. 2007. Rhizosphere communication of plants, parasitic plants and AM fungi. Trends Plant Sci. 12:224-230.

Boyer, M., Bally, R., Perrotto, S., Chaintreuil, C., and Wisniewski-Dyé, F. 2008. A quorum-quenching approach to identify quorum-sensingregulated functions in Azospirillum lipoferum. Res. Microbiol.159:699708.

Brazelton, J. N., Pfeufer, E. E., Sweat, T. A., Gardener, B. B., and Coenen, C. 2008. 2,4-diacetylphloroglucinol alters plant root development. Mol. Plant-Microbe Interact. 21:1349-1358.

Brodhagen, M., Henkels, M. D., and Loper, J. E. 2004. Positive autoregulation and signaling properties of pyoluteorin, an antibiotic produced by the biological control organism Pseudomonas fluorescens Pf-5. Appl. Environ. Microbiol. 70:1758-1766.

Brown, M. R. W., and Kornberg, A. 2008. The long and short of it polyphosphate, PPK and bacterial survival. Trends Biochem. Sci. 33:284290 .

Chávez de Paz, L. E. 2009. Image analysis software based on color segmentation for characterization of viability and physiological activity of biofilms. Appl. Environ. Microbiol. 15:1734-1739.

Chilton, M. D., Currier, T. C., Farrand, S. K., Bendich, A. J., Gordon, M. P., and Nester, E. W. 1974. Agrobacterium tumefaciens DNA and PS8 bacteriophage DNA not detected in crown gall tumors. Proc. Natl. Acad. Sci. U.S.A. 71:3672-3676.

Cooper, J. E. 2007. Early interactions between legumes and rhizobia: Disclosing complexity in a molecular dialogue. J. Appl. Microbiol. 103:1355-1365.

Costacurta, A., and Vanderleyden, J. 1995. Synthesis of phytohormones by plant-associated bacteria. Crit. Rev. Microbiol. 21:1-18.

Couillerot, O., Prigent-Combaret, C., Caballero-Mellado, J., and MoënneLoccoz, Y. 2009. Pseudomonas fluorescens and closely-related fluorescent pseudomonads as biocontrol agents of soil-borne phytopathogens. Lett. Appl. Microbiol. 48:505-512.

Creus, C. M., Graziano, M., Casanovas, E. M., Pereyra, M. A., Simontacchi, M., Puntarulo, S., Barassi, C. A., and Lamattina, L. 2005. Nitric oxide is involved in the Azospirillum brasilense induced lateral root formation in tomato. Planta 221:297-303.

Croes, C. L., Moens, S., Vanbastelaere, E., Vanderleyden, J., and Michiels, K. W. 1993. The polar flagellum mediates Azospirillum brasilense adsorption to wheat roots. J. Gen. Microbiol. 139:2261-2269.

Cronin, D., Moënne-Loccoz, Y., Fenton, A., Dunne, C., Dowling, D. N., and O'Gara, F. 1997. Ecological interaction of a biocontrol Pseudomonas fluorescens strain producing 2,4-diacetylphloroglucinol with the soft rot potato pathogen Erwinia carotovora subsp. atroseptica. FEMS (Fed. Eur. Microbiol. Soc.) Microbiol. Ecol. 23:95-106.

Daniels, R., Vanderleyden, J., and Michiels, J. 2004. Quorum sensing and swarming migration in bacteria. FEMS (Fed. Eur. Microbiol. Soc.) Microbiol. Rev. 28:261-289.

Daniels, R., Reynaert, S., Hoekstra, H., Verreth, C., Janssens, J., Braeken, K., Fauvart, M., Beullens, S., Heusdens, C., Lambrichts, I., De Vos, D. E., Vanderleyden, J., Vermant, J., and Michiels, J. 2006. Quorum signal molecules as biosurfactants affecting swarming in Rhizobium etli. Proc. Natl. Acad. Sci. U.S.A. 103:14965-14970.

Daugherty, P. S., Iverson, B. L., and Georgiou, G. 2000. Flow cytometric screening of cell-based libraries. J. Immunol. Methods 243:211-227.

Degelau, A., Scheper, T., Bailey, J. E., and Guske, C. 1995. Fluorometric measurement of poly-beta hydroxybutyrate in Alcaligenes eutrophus by flow-cytometry and spectrofluorometry. Appl. Microbiol. Biotechnol. 42:653-657.

de Lorenzo, V., and Timmis, K. N. 1994. Analysis and construction of stable phenotypes in gram negative bacteria with Tn5- and Tn10-derived minitransposons. Methods Enzymol. 235:386-405.

de Souza, J. T., Arnould, C., Deulvot, C., Lemanceau, P., GianinazziPearson, V., and Raaijmakers, J. M. 2003. Effect of 2,4-diacetylphloroglucinol on Pythium: Cellular responses and variation in sensitivity among propagules and species. Phytopathology 93:966-975.

Dobbelaere, S., Croonenborghs, A., Thys, A., Vande Broek, A., and Vanderleyden, J. 1999. Phytostimulatory effect of Azospirillum brasilense wild type and mutant strains altered in IAA production on wheat. Plant Soil 212:155-164.

Dobbelaere, S., Croonenborghs, A., Thys, A., Ptacek, D., Vanderleyden, J., Dutto, P., Labandera-Gonzalez, C., Caballero-Mellado, J., Aguirre, J. F., Kapulnik, Y., Brener, S., Burdman, S., Kadouri, D., Sarig, S., and Okon, Y. 2001. Responses of agronomically important crops to inoculation with Azospirillum. Aust. J. Plant Physiol. 28:871-879. 
Dobbelaere, S., Vanderleyden, J., and Okon, Y. 2003. Plant growth-promoting effects of diazotrophs in the rhizosphere. Crit. Rev. Plant Sci. 22:107-149.

Dorel, C., Vidal, O., Prigent-Combaret, C., Vallet, I., and Lejeune, P. 1999. Involvement of the Cpx signal transduction pathway of $E$. coli in biofilm formation. FEMS (Fed. Eur. Microbiol. Soc.) Microbiol. Lett 178:169-175

El Zemrany, H., Cortet, J., Lutz, M. P., Chabert, A., Baudoin, E., Haurat, J., Maughan, N., Felix, D., Défago, G., Bally, R., and Moënne-Loccoz, Y. 2006. Field survival of the phytostimulator Azospirillum lipoferum CRT1 and functional impact on maize crop, biodegradation of crop residues, and soil faunal indicators in a context of decreasing nitrogen fertilisation. Soil Biol. Biochem. 38:1712-1726.

Fiedler, S., Steinbuchel, A., and Rehm, B. H. A. 2002. The role of the fatty acid beta-oxidation multienzyme complex from Pseudomonas oleovorans in polyhydroxyalkanoate biosynthesis: Molecular characterization of the fadBA operon from P. oleovorans and of the enoyl-CoA hydratase genes phaJ from P. oleovorans and Pseudomonas putida. Arch. Microbiol. 178:149-160.

Frapolli, M., Moënne-Loccoz, Y., Meyer, J., and Défago, G. 2008. A new DGGE protocol targeting 2,4-diacetylphloroglucinol biosynthetic gene phlD from phylogenetically contrasted biocontrol pseudomonads for assessment of disease-suppressive soils. FEMS (Fed. Eur. Microbiol. Soc.) Microbiol. Ecol. 64:468-481.

Gibson, K. E., Kobayashi, H., and Walker, G. C. 2008. Molecular determinants of a symbiotic chronic infection. Annu. Rev. Genet. 42:413-441.

Glickmann, E., and Dessaux, Y. 1995. A critical examination of the specificity of the Salkowski reagent for indolic compounds produced by phytopathogenic bacteria. Appl. Environ. Microbiol. 61:793-796.

Greer-Phillips, S. E., Stephens, B. B., and Alexandre, G. 2004. An energy taxis transducer promotes root colonization by Azospirillum brasilense. J. Bacteriol. 186:6595-6604.

Haas, D., and Keel, C. 2003. Regulation of antibiotic production in rootcolonizing Pseudomonas spp. and relevance for biological control of plant disease. Annu. Rev. Phytopathol. 41:117-153.

Hirsch, A. M., Bauer, W. D., Bird, D. M., Cullimore, J., Tyler, B., and Yoder, J. I. 2003. Molecular signals and receptors: Controlling rhizosphere interactions between plants and other organisms. Ecology 84:858-868

Iavicoli, A., Boutet, E., Buchala, A., and Métraux, J. P. 2003. Induced systemic resistance in Arabidopsis thaliana in response to root inoculation with Pseudomonas fluorescens CHA0. Mol. Plant-Microbe Interact. 16:851-858

Ishikawa, J., and Hotta, K. 1999. FramePlot: A new implementation of the frame analysis for predicting protein-coding regions in bacterial DNA with a high $\mathrm{G}+\mathrm{C}$ content. FEMS (Fed. Eur. Microbiol. Soc.) Microbiol. Lett. 174:251-253

Kadouri, D., Jurkevitch, E., and Okon, Y. 2003. Involvement of the reserve material poly-beta-hydroxybutyrate in Azospirillum brasilense stress endurance and root colonization. Appl. Environ. Microbiol. 69:32443250

Kamnev, A. A., Sadovnikova, J. N., Tarantilis, P. A., Polissiou, M. G., and Antonyuk, L. P. 2008. Responses of Azospirillum brasilense to nitrogen deficiency and to wheat lectin: A diffuse reflectance infrared fourier transform (DRIFT) spectroscopic study. Microb. Ecol. 56:615-624.

Keel, C., Schnider, U., Maurhofer, M., Voisard, C., Laville, J., Burger, U., Wirthner, P., Haas, D., and Défago, G. 1992. Suppression of root diseases by Pseudomonas fluorescens CHA0: Importance of the bacterial secondary metabolite 2,4-diacetylphloroglucinol. Mol. Plant-Microbe Interact. 5:4-13.

Kyselkova, M., Kopecky, J., Frapolli, M., Défago, G., Sagova-Mareckova, M., Grundmann, G. L., and Moënne-Loccoz, Y. 2009. Comparison of rhizobacterial community composition in soil suppressive or conducive to tobacco black root rot disease. ISME J. 3:1127-1138.

Lambrecht, M., Okon, Y., Vande Broek, A., and Vanderleyden, J. 2000. Indole-3-acetic acid: A reciprocal signalling molecule in bacteria-plant interactions. Trends Microbiol. 8:298-300.

Lutz, M. P., Wenger, S., Maurhofer, M., Défago, G., and Duffy, B. 2004. Signaling between bacterial and fungal biocontrol agents in a strain mixture. FEMS (Fed. Eur. Microbiol. Soc.) Microbiol. Ecol. 48:447455

Miché, L., and Balandreau, J. 2001. Effects of rice seed surface sterilization with hypochlorite on inoculated Burkholderia vietnamiensis. Appl. Environ. Microbiol. 67:3046-3052.

Miché, L., Bouillant, M. L., Rohr, R., Sallé, G., and Bally, R. 2000. Physiological and cytological studies on the inhibition of striga seed germination by the plant growth-promoting bacterium Azospirillum brasilense. Eur. J. Plant Pathol. 106:347-351.

Molina-Favero, C., Creus, C. M., Simontacchi, M., Puntarulo, S., and Lamattina, L. 2008. Aerobic nitric oxide production by Azospirillum brasilense Sp245 and its influence on root architecture in tomato. Mol. Plant-Microbe Interact. 21:1001-1009.

Naiman, A. D., Latronico, A., and de Salamone, I. E. G. 2009. Inoculation of wheat with Azospirillum brasilense and Pseudomonas fluorescens: Impact on the production and culturable rhizosphere microflora. Eur. J. Soil Biol. 45:44-51.

Nelson, L. M., and Knowles, R. 1978. Effect of oxygen and nitrate on nitrogen fixation and denitrification by Azospirillum brasilense grown in continuous culture. Can. J. Microbiol. 24:1395-1403.

Pesavento, C., and Hengge, R. 2009. Bacterial nucleotide-based second messengers. Curr. Opin. Microbiol. 12:170-176.

Phillips, D. A., Fox, T. C., King, M. D., Bhuvaneswari, T. V., and Teuber, L. R. 2004. Microbial products trigger amino acid exudation from plant roots. Plant Physiol. 136:2887-2894.

Pieterse, C. M. J., Van Pelt, J. A., Verhagen, B. W. M., Ton, J., Van Wees, S. C. M., Leon-Kloosterziel, K. M., and Van Loon, L. C. 2003. Induced systemic resistance by plant growth-promoting rhizobacteria. Symbiosis 35:39-54.

Pothier, J. F., Wisniewski-Dyé, F., Weiss-Gayet, M., Moënne-Loccoz, Y., and Prigent-Combaret, C. 2007. Promoter-trap identification of wheat seed extract-induced genes in the plant-growth-promoting rhizobacterium Azospirillum brasilense Sp245. Microbiology 153:3608-3622.

Prell, J., White, J. P., Bourdes, A., Bunnewell, S., Bongaerts, R. J., and Poole, P. S. 2009. Legumes regulate Rhizobium bacteroid development and persistence by the supply of branched-chain amino acids. Proc. Natl. Acad. Sci. U.S.A. 106:12477-12482.

Prigent-Combaret, C., Blaha, D., Pothier, J. F., Vial, L., Poirier, M. A., Wisniewski-Dyé, F., and Moënne-Loccoz, Y. 2008. Physical organization and phylogenetic analysis of $a c d R$ as leucine-responsive regulator of the 1-aminocyclopropane-1-carboxylate deaminase gene acdS in phytobeneficial Azospirillum lipoferum 4B and other proteobacteria. FEMS (Fed. Eur. Microbiol. Soc.) Microbiol. Ecol. 65:202-219.

Ramey, B. E., Koutsoudis, M., von Bodman, S. B., and Fuqua, C. 2004 Biofilm formation in plant-microbe associations. Curr. Opin. Microbiol. 7:602-609.

Rediers, H., Rainey, P. B., Vanderleyden, J., and De Mot, R. 2005. Unraveling the secret lives of bacteria: Use of in vivo expression technology and differential fluorescence induction promoter traps as tools for exploring niche-specific gene expression. Microbiol. Mol. Biol. Rev. 69:217-261.

Rubio, L. M., and Ludden, P. W. 2008. Biosynthesis of the iron-molybdenum cofactor of nitrogenase. Annu. Rev. Microbiol. 62:93-111.

Rudrappa, T., Biedrzycki, M. L., and Bais, H. P. 2008. Causes and consequences of plant-associated biofilms. FEMS (Fed. Eur. Microbiol. Soc.) Microbiol. Ecol. 64:153-166.

Sambrook, J., Fritsch, E. F., and Maniatis, T. 1989. Molecular Cloning: A Laboratory Manual, 2nd ed. Cold Spring Harbor Laboratory Press, Cold Spring Harbor, NY, U.S.A

Sanguin, H., Sarniguet, A., Gazengel, K., Moënne-Loccoz, Y., and Grundmann, G. L. 2009. Rhizosphere bacterial communities associated with disease suppressiveness stages of take-all decline in wheat monoculture. New Phytol. 184:694-707.

Shanahan, P., O’Sullivan D, J., Simpson, P., Glennon, J. D., and O'Gara, F. 1992. Isolation of 2,4-diacetylphloroglucinol from a fluorescent pseudomonad and investigation of physiological parameters influencing its production. Appl. Environ. Microbiol. 58:353-358.

Silby, M. W., and Levy, S. B. 2004. Use of in vivo expression technology to identify genes important in growth and survival of Pseudomonas fluorescens Pf0-1 in soil: Discovery of expressed sequences with novel genetic organization. J. Bacteriol. 186:7411-7419.

Silby, M. W., Rainey, P. B., and Levy, S. B. 2004. IVET experiments in Pseudomonas fluorescens reveal cryptic promoters at loci associated with recognizable overlapping genes. Microbiology 150:518-520.

Spaink, H. P. 2000. Root nodulation and infection factors produced by rhizobial bacteria. Annu. Rev. Microbiol. 54:257-288.

Stojiljkovic, I., Baümler, A. J., and Heffron, F. 1995. Ethanolamine utilization in Salmonella typhimurium: Nucleotide sequence, protein expression, and mutational analysis of the cchA cchB eutE eutJ eutG eutH gene cluster. J. Bacteriol. 177:1357-1366.

Teplitski, M., Robinson, J. B., and Bauer, W. D. 2000. Plants secrete substances that mimic bacterial $\mathrm{N}$-acyl homoserine lactone signal activities and affect population density-dependent behaviors in associated bacteria. Mol. Plant-Microbe Interact. 13:637-648.

Turnbull, G. A., Morgan, J. A., Whipps, J. M., and Saunders, J. R. 2001 The role of bacterial motility in the survival and spread of Pseudomonas fluorescens in soil and in the attachment and colonisation of wheat roots. FEMS (Fed. Eur. Microbiol. Soc.) Microbiol. Ecol. 36:21-31.

Vázquez, M. M., César, S., Azcón, R., and Barea, J. M. 2000. Interactions between arbuscular mycorrhizal fungi and other microbial inoculants (Azospirillum, Pseudomonas, Trichoderma) and their effects on micro- 
bial population and enzyme activities in the rhizosphere of maize plants. Appl. Soil Ecol. 13:261-272.

Wei, H. L., and Zhang, L. Q. 2006. Quorum-sensing system influences root colonization and biological control ability in Pseudomonas fluorescens 2P24. Antonie Leeuwenhoek 89:267-280.

Weller, D. M. 2007. Pseudomonas biocontrol agents of soilborne pathogens: Looking back over 30 years. Phytopathology 97:250-256.

Weller, D. M., Landa, B. B., Mavrodi, O. V., Schroeder, K. L., De La Fuente, L., Bankhead, S. B., Molar, R. A., Bonsall, R. F., Mavrodi, D. V., and Thomashow, L. S. 2007. Role of 2,4-diacetylphloroglucinolproducing fluorescent Pseudomonas spp. in the defense of plant roots. Plant Biol. 9:4-20.

Zamudio, M., and Bastarrachea, F. 1994. Adhesiveness and root hair de- formation capacity of Azospirillum strains for wheat seedlings. Soil Biol. Biochem. 26:791-797.

\section{AUTHOR-RECOMMENDED INTERNET RESOURCES}

National Center for Biotechnology Information BLAST database: www.ncbi.nlm.nih.gov/BLAST

National Institutes of Health BLASTN and BLASTX database: http://www.ncbi.nlm.nih.gov/BLAST

National Institutes of Health Watson database: watson.nih.go.jp

Oak Ridge National Laboratory Azospirillum brasilense Sp245 analysis data: genome.ornl.gov/microbial/abra/23apr08 